ISSN: 1399-0047

journals.iucr.org/d

\title{
Cholesterol oxidase: ultrahigh-resolution crystal structure and multipolar atom model-based analysis
}

\section{Bartosz Zarychta, Artem Lyubimov, Maqsood Ahmed, Parthapratim Munshi, Benoît Guillot, Alice Vrielink and Christian Jelsch}

Acta Cryst. (2015). D71, 954-968

\section{\# IUCr Journals} CRYSTALLOGRAPHY JOURNALS ONLINE

Copyright (C) International Union of Crystallography

Author(s) of this paper may load this reprint on their own web site or institutional repository provided that this cover page is retained. Republication of this article or its storage in electronic databases other than as specified above is not permitted without prior permission in writing from the IUCr.

For further information see http://journals.iucr.org/services/authorrights.html
} 
BIOLOGICAL CRYSTALLOGRAPHY

ISSN 1399-0047

Received 29 September 2014

Accepted 4 February 2015

Edited by V. Y. Lunin, Russian Academy of Sciences, Russia

Keywords: cholesterol oxidase.

PDB reference: cholesterol oxidase, 4rek

Supporting information: this article has supporting information at journals.iucr.org/d

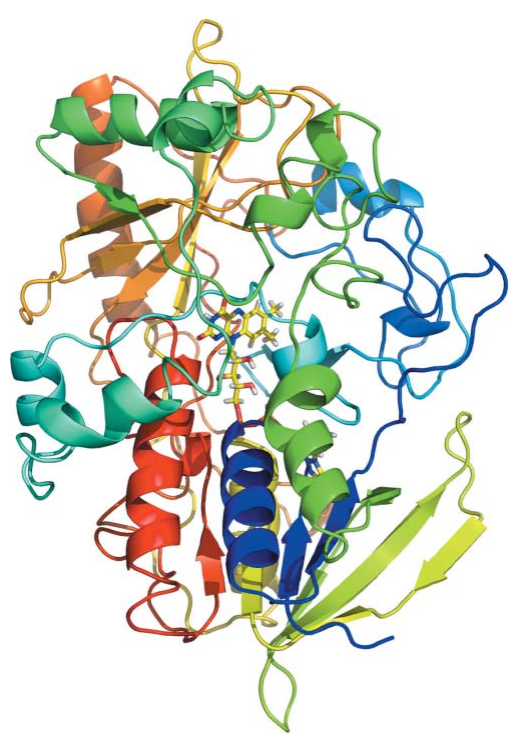

(C) 2015 International Union of Crystallography

\section{Cholesterol oxidase: ultrahigh-resolution crystal structure and multipolar atom model-based analysis}

\author{
Bartosz Zarychta, ${ }^{\mathrm{a}, \mathrm{b}}$ Artem Lyubimov, ${ }^{\mathrm{c}}$ Maqsood Ahmed, ${ }^{\mathrm{a}, \mathrm{d}}$ Parthapratim \\ Munshi, ${ }^{\mathrm{a}, \mathrm{e}}$ Benoît Guillot, ${ }^{\mathrm{a}}$ Alice Vrielink ${ }^{\mathrm{f}}$ and Christian Jelsch ${ }^{\mathrm{a} *}$
}

aLaboratoire de Cristallographie, Résonance Magnétique et Modélisations (CRM2), CNRS, UMR 7036, Institut Jean Barriol, Faculté des Sciences et Technologies, Université de Lorraine, BP 70239, 54506 Vandoeuvre-lès-Nancy CEDEX,

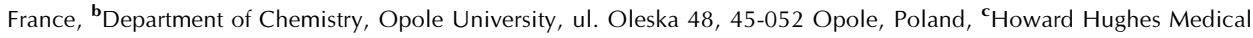
Institute, Stanford, CA 94305-5432, USA, dDepartment of Chemistry, The Islamia University of Bahawalpur, Bahawalpur, Pakistan, ${ }^{\mathbf{e}}$ Department of Chemistry and Center for Informatics, School of Natural Sciences, Shiv Nadar University, NH91, Tehsil Dadri, Gautam Buddha Nagar, Uttar Pradesh 201 314, India, and 'School of Chemistry and Biochemistry, University of Western Australia, 35 Stirling Highway, Crawley, WA 6009, Australia. ${ }^{*}$ Correspondence e-mail: christian.jelsch@univ-lorraine.fr

Examination of protein structure at the subatomic level is required to improve the understanding of enzymatic function. For this purpose, X-ray diffraction data have been collected at $100 \mathrm{~K}$ from cholesterol oxidase crystals using synchrotron radiation to an optical resolution of $0.94 \AA$. After refinement using the spherical atom model, nonmodelled bonding peaks were detected in the Fourier residual electron density on some of the individual bonds. Well defined bond density was observed in the peptide plane after averaging maps on the residues with the lowest thermal motion. The multipolar electron density of the protein-cofactor complex was modelled by transfer of the ELMAM2 chargedensity database, and the topology of the intermolecular interactions between the protein and the flavin adenine dinucleotide (FAD) cofactor was subsequently investigated. Taking advantage of the high resolution of the structure, the stereochemistry of main-chain bond lengths and of $\mathrm{C}=\mathrm{O} \cdots \mathrm{H}-\mathrm{N}$ hydrogen bonds was analyzed with respect to the different secondary-structure elements.

\section{Introduction}

Cholesterol oxidase (ChOx) is a $55 \mathrm{kDa}$ secreted bacterial enzyme that binds the flavin adenine dinucleotide (FAD) cofactor (reviewed in Vrielink \& Ghisla, 2009). Two main forms of the enzyme have been identified (for a review, see Sampson \& Vrielink, 2003). In form I the FAD cofactor is noncovalently bound to the protein, whereas in form II the FAD group is covalently bound to His 121 . The noncovalent forms of the flavoprotein are members of the GMC (glucose, methanol, choline) oxidoreductase family of flavoenzymes (Cavener, 1992), in which two residues, His447 and Asn485, which have been shown to be involved in substrate oxidation, are semi-conserved (Kass \& Sampson, 1998; Yue et al., 1999; Yin et al., 2001).

This water-soluble enzyme is mainly used in serum cholesterol assays. Cholesterol oxidases are bifunctional enzymes that catalyze two reactions in a single active site. The first is the oxidation of cholesterol to cholest-5-en-3-one and the second is its isomerization to cholest-4-en-3-one (Stadtman et al., 1954; Flegg, 1973). The oxidation of the hydroxyl group on the steroid substrate requires a FAD cofactor that is concomitantly reduced (Fig. 1). The cofactor is re-oxidized by the reduction of molecular oxygen to generate hydrogen peroxide. The presence of hydrogen peroxide can be detected through a 
colorimetric assay, which forms the basis of clinical assays for the determination of serum cholesterol.

ChOx-utilizing bacteria can be classified into two types: nonpathogenic and pathogenic. Nonpathogenic bacteria, for example streptomycetes and the fast-growing mycobacteria, can utilize cholesterol as their carbon source and up-regulate the expression of cholesterol oxidase in the presence of cholesterol (Av-Gay \& Sobouti, 2000). Pathogenic bacteria, for example Rhodococcus equi, require cholesterol oxidase for infection of the host macrophage; cholesterol also regulates the expression of the enzyme in these organisms (Navas et al., 2001). The role of the enzyme in pathogenesis is assumed to be the alteration of the physical structure of the lipid membrane by converting cholesterol into cholest-4-en-3-one (Shen et al., 1997).

$\mathrm{ChOx}$ also possesses insecticidal properties against Coeloptera larvae, which are agricultural pests, and is being developed for use in agricultural crop treatment (Corbin et al., 1998, 2001). The crystal structure of the ChOx protein has been determined at increasing resolutions, under different $\mathrm{pH}$ conditions and as different mutant forms (Yue et al., 1999; Lario et al., 2003; Lario \& Vrielink, 2003; Lyubimov et al., 2006, 2007, 2009). In all of these reports different aspects of the enzyme structure were explored to understand its catalytic mechanism. It has been reported that the dioxygen molecule reaches the active site via a tunnel (Lario et al., 2003). This tunnel, lined with hydrophobic residues, is visible in the type II enzyme at $1.7 \AA$ resolution (Coulombe et al., 2001), whereas in the type I enzyme, in which the cofactor is noncovalently bound to the protein, the tunnel becomes clear only at $0.95 \AA$ resolution (Lario et al., 2003). In the former case, the tunnel is gated by Arg477, whereas in the latter case Asn485 gates the active-site end of the tunnel. Asn 485 has also been shown to play a role in stabilizing the reduced flavin cofactor through a $\mathrm{C}-\mathrm{H} \cdots \pi$ interaction with the isoalloxazine moiety (Yin et al., 2001; Chen et al., 2008). Various residues close to the active site exist in multiple conformations which are proposed to be involved in the gating of the tunnel. The residues lining the tunnel are hydrophobic in nature (Lario et al., 2003).

The study of the electrostatic potential of molecules is highly important as it provides an opportunity to understand the specificity of protein-ligand binding and also helps in understanding the phenomenon of molecular recognition. Electron density at the subatomic level can now almost routinely be observed for small-molecule crystals studied at ultrahigh resolution, mainly owing to the state-of-the-art equipment available to contemporary crystallographers. In contrast, for larger molecules (including proteins), electron density can be modelled at lower resolution through the application of electron-density transferability principles (Muzet et al., 2003; Guillot et al., 2008; Dominiak et al., 2009; Johnas et al., 2009).

In this method, the electron-density parameters studied from small molecules are stored in the ELMAM2 database of multipolar atoms (Domagała et al., 2011, 2012). Upon database transfer, chemical atom types are identified and their electron-density parameters are retrieved. Derived molecular properties such as electrostatic potential can subsequently be computed within the transferability approximation. This method is particularly useful in the case of proteins, as they rarely diffract to subatomic resolution. Only about 20 of the protein structures currently reported in the PDB (Bernstein et al., 1977; Berman, 2000) have been refined to resolutions at or higher than $0.75 \AA$. The topology of covalent bonds and hydrogen bonds in the hen egg-white lysozyme active-site structure at $0.65 \AA$ resolution have recently been analyzed. The Bader (1991) quantum theory of atoms in molecules was applied to electron-density maps obtained from ELMAM2 database multipole transfer (Held \& van Smaalen, 2014).

In the present study, the structure of cholesterol oxidase is refined using synchrotron data measured to $0.74 \AA$ resolution. This is the highest resolution data set that has been achieved for this protein to date and is exceptional for a protein of this size (more than 500 residues). The high-resolution data yield good-quality electron-density maps in which it is possible to precisely locate many of the $\mathrm{H}$ atoms using difference Fourier

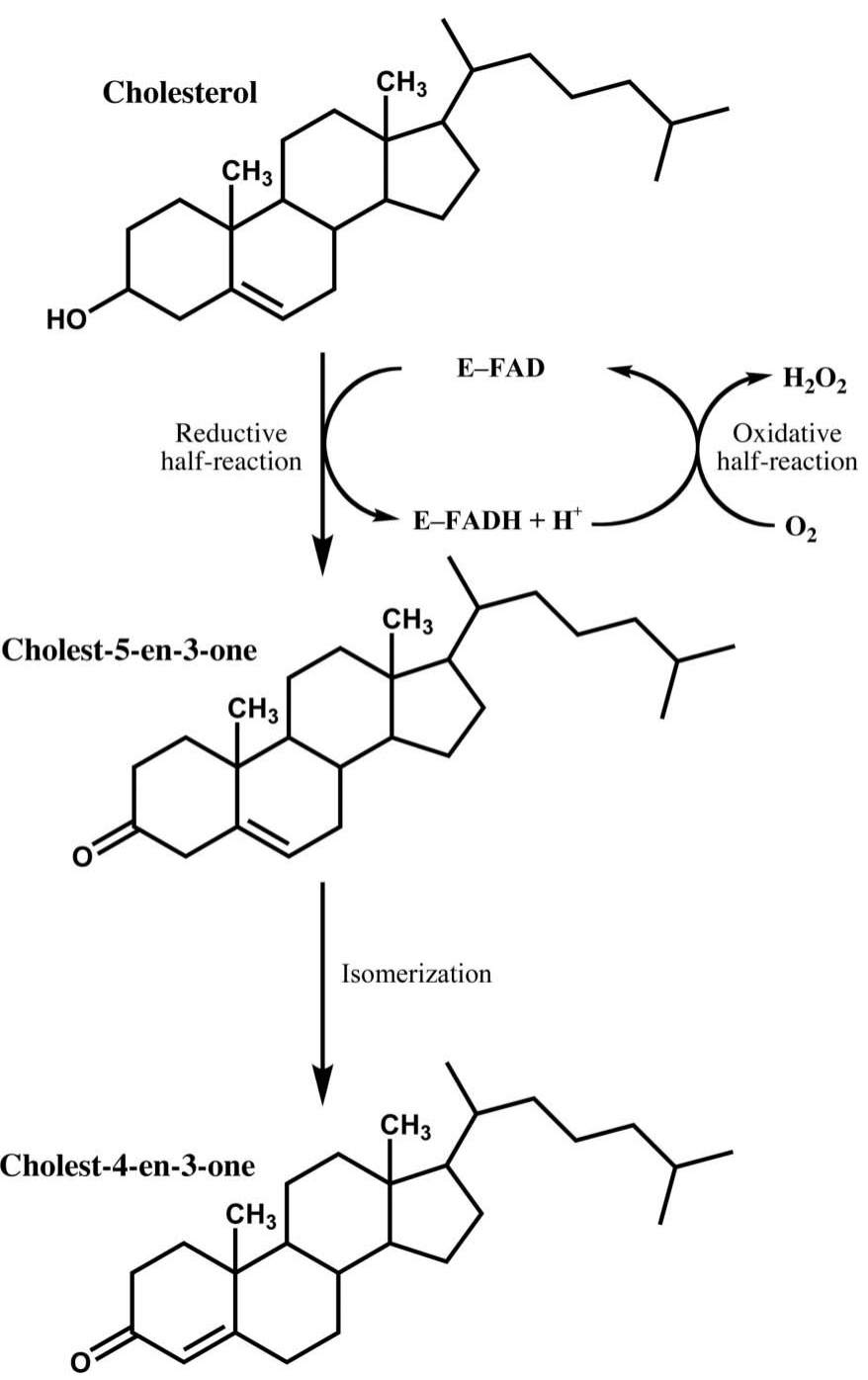

Figure 1

Scheme showing the oxidation and isomerization reactions of cholesterol oxidase. 
maps, including the hydrogen-bonding networks connecting water molecules. The structure displays an average atomic thermal motion that is too high compared to the requirements for charge-density refinement. Conversely, in human aldose reductase a large number of atoms had $B_{\text {eq }}<4 \AA^{2}$, which enabled a charge-density refinement of the polypeptide main chain using chemical equivalence constraints (Guillot et al., 2008). The precision of atomic coordinates, including $\mathrm{H}$ atoms, however, supports the application of the transferability principle towards the ChOx model. Therefore, an electron-density model of ChOx was constructed based on the ELMAM2 multipolar atoms database (Domagała et al., 2011, 2012). This led to a computation of the derived electrostatic potential at the interacting surface between the protein and the FAD cofactor. Furthermore, the topological properties of proteincofactor interactions as well as the intramolecular interactions of the FAD could be quantified. The insights obtained from this work provide an overview regarding the protein-FAD cofactor recognition and electrostatic interaction.

\section{Materials and methods}

\subsection{Crystallization}

Recombinant Streptomyces sp. ChOx was expressed and purified as described previously (Yue et al., 1999). The pure enzyme was concentrated to $6.5 \mathrm{mg} \mathrm{ml}^{-1}$ in $10 \mathrm{~m} M$ HEPES buffer. Crystals were grown by the hanging-drop vapourdiffusion method in 24-well crystallization plates (Hampton Research, California, USA). The crystallization solution was composed of 9-11\% poly(ethylene glycol) (PEG) molecular weight $8000,75 \mathrm{mM} \mathrm{MnSO}$, $100 \mathrm{~m} M$ sodium cacodylate buffer $\mathrm{pH}$ 5.2. Drops consisting of $1.0 \mu$ l crystallization solution and $1.0 \mu \mathrm{l}$ wild-type protein solution were suspended over a well containing $1.0 \mathrm{ml}$ crystallization solution. Drops were streak-seeded using ChOx crystals grown previously. Small crystals appeared overnight and grew to a suitable size for data collection within two weeks.

\subsection{Crystallographic data collection and processing}

X-ray diffraction data were collected from a total of five crystals on beamlines 9-2 and 11-1 at Stanford Synchrotron Radiation Laboratory (SSRL). Four crystals were used to collect ultrahigh-resolution data (1.0-0.74 $\AA$ ). A fifth crystal was used to collect three low exposure time sweeps of data; firstly to atomic resolution $(\sim 0.95 \AA)$, then to the maximum attainable resolution $(\sim 0.74 \AA)$ and finally, using an attenuated beam, to medium resolution $(\sim 1.8 \AA)$. The lowexposure sweeps were necessary to avoid overloaded reflections at low resolution.

Diffraction images were processed with the $d^{*} T R E K$ software suite (Pflugrath, 1999). The final data-processing statistics are shown in Table 1 . The scaled data were converted to MTZ format using the CCP4 software suite (Winn et al., 2011) for initial refinement, and $5 \%$ of the reflections were randomly selected as a test set and excluded from all refinement steps. The overall completeness of the diffraction data is $78.8 \%$. The
Table 1

Crystallographic data-collection, data-reduction and structure-refinement statistics using a spherical atom model.

R.m.s.d., root-mean-square deviation. Values in parentheses are for the outermost shell.

\begin{tabular}{|c|c|}
\hline \multicolumn{2}{|l|}{ Data collection } \\
\hline Space group & $P 2_{1}$ \\
\hline Unit-cell parameters $\left(\AA{ }^{\circ},{ }^{\circ}\right)$ & $\begin{array}{c}a=51.24, b=72.92, \\
\quad c=63.01, \beta=105.13\end{array}$ \\
\hline Temperature $(\mathrm{K})$ & 100 \\
\hline Total No. of reflections & 3141008 \\
\hline No. of unique reflections & 465386 \\
\hline Optical resolution $(\AA)$ & 0.94 \\
\hline Resolution $(\AA)$ & $0.74(0.80-0.74)$ \\
\hline$R_{\text {merge }}(\%)$ & $5.2(64.4)$ \\
\hline$\langle I / \sigma(I)\rangle$ & $10.7(0.7)$ \\
\hline Completeness (\%) & $78.8(21.2)$ \\
\hline Multiplicity & $6.75(1.15)$ \\
\hline \multicolumn{2}{|l|}{ Refinement } \\
\hline$R_{\text {work }} / R_{\text {free }}$ (all data) & $0.116 / 0.123$ \\
\hline No. of atoms (iso/aniso) & $4309 / 5143$ \\
\hline No. of occupancies refined & 2725 \\
\hline No. of $I(h k l)$ data:No. of parameters ratio & 7.2 \\
\hline$F_{\mathrm{o}}-F_{\mathrm{c}}$ map r.m.s. value $\left(\mathrm{e} \AA^{-3}\right)$ & 0.0066 \\
\hline \multicolumn{2}{|c|}{ Isotropic $B$ factors (without $\mathrm{H})\left(\right.$ minimum/average) $\left(\AA^{2}\right)$} \\
\hline Protein main chain & $5.0 / 8.3 \pm 2.3$ \\
\hline Protein side chain & $5.1 / 9.8 \pm 2.8$ \\
\hline FAD & $4.7 / 5.5 \pm 0.6$ \\
\hline R.m.s.d, bond lengths $(\AA)$ & 0.013 \\
\hline R.m.s.d, bond angles $\left({ }^{\circ}\right)$ & 1.595 \\
\hline
\end{tabular}

completeness at very low resolution $d<12.7 \AA$ is $93 \%$ (see Supporting Information). The optical resolution (Urzhumtseva et al., 2013) of the diffraction data, computed using SFCHECK (Vaguine et al., 1999), is $0.94 \AA$.

\subsection{Structure refinement}

A previous model of the enzyme refined with data measured to $0.95 \AA$ resolution (Lario \& Vrielink, 2003) was used as the starting model for the current refinement of ChOx. The structure was refined with PHENIX (Afonine et al., 2012), using the maximum-likelihood refinement method and anisotropic thermal motion parameters for the non-H atoms. The structure was refined using all reflections with no resolution or $I / \sigma(I)$ cutoff, as recommended by Karplus \& Diederichs (2012), although the diffraction data beyond $0.8 \AA$ resolution are incomplete and weak. Bulk-solvent correction and anisotropic scaling were applied. Water molecules were refined automatically by $P H E N I X$ but were also handled manually; their occupancy factors were refined. The refinement details are listed in Table 1. The structure was not refined using a multipolar atom model because, unlike crambin (Jelsch et al., 2000) and aldose reductase (Guillot et al., 2008), the Fourier residual density did not show systematic visible, nonmodelled, deformation electron density on individual covalent bonds.

\subsection{Electron-density transfer and analysis}

Electronic properties of macromolecular systems can be studied by the use of transferability even if an experimental charge-density analysis is not possible. The protein model obtained from PHENIX was imported into the MoPro 
software (Jelsch et al., 2005) and the electron-density parameters from the ELMAM2 library (Domagała et al., 2011) were transferred to the structure.

After electron-density transfer, the $\mathrm{H}$-atom positions were set to the standard neutron diffraction $\mathrm{H}-X$ bond lengths (Allen et al., 2006). On the basis of the transferred electrondensity parameters, the electrostatic potential generated by the cofactor FAD and the active-site region of the protein were calculated with the VMoPro software using the MoProViewer (Guillot, 2011) graphical interface. Atom types that are not present in the ELMAM2 database, notably the atoms of the pyrophosphate group, were derived from the $\mathrm{NAD}^{+}$cofactor, which has been studied by charge-density analysis (Guillot et al., 2003).

\section{Results and discussion}

\subsection{Protein structure}

A ribbon view of the $\mathrm{ChOx}$ protein structure is shown in Fig. 2. The structure was refined to $R_{\text {work }}$ and $R_{\text {free }}$ values of 11.6 and $12.3 \%$, respectively. The final model contains 499 visible amino acids, a FAD cofactor (Fig. 3) and 897 water molecules. The Ramachandran plot (Ramachandran et al., 1963) of the refined protein structure obtained from MolProbity (Chen et al., 2010) is shown in Fig. 4. Residue Val217 is slightly outside the favourable regions of the Ramachandran plot, as was seen in previous crystal structures of ChOx. $98 \%$ of the amino acids were observed in favoured regions of the Ramachandran plot and $99.8 \%$ were observed in allowed regions. The final refined coordinates and structure

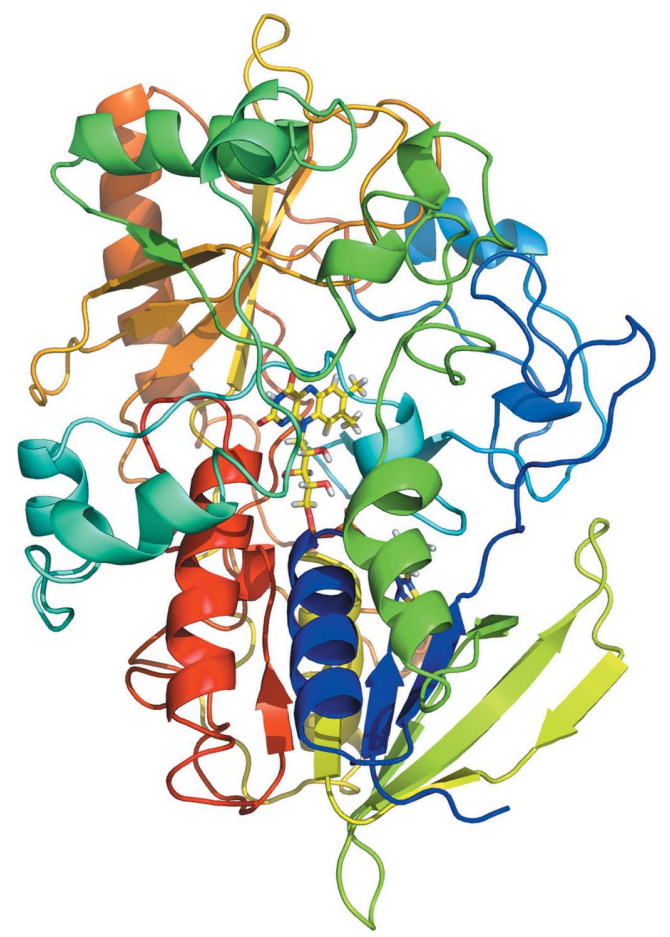

Figure 2

Ribbon cartoon model of the cholesterol oxidase protein structure. The FAD cofactor is shown as a stick model. factors have been deposited in the Protein Data Bank (PDB) as entry 4rek.

The $2 F_{\mathrm{o}}-F_{\mathrm{c}}$ electron-density map for the FAD cofactor from structural refinement using PHENIX is shown in Fig. 5. The well defined FAD cofactor has atoms with $B_{\text {eq }}$ factors in the range 4.7-7.8 $\AA^{2}$. The electron density contoured at $5 \sigma$ provides a view of the ellipsoidal motion around non-H atoms and gives a qualitative view of the anisotropy of the atomic thermal motions.

\subsection{Protein charge-density model}

The very high resolution of the collected data can be related to the $B$ factor obtained from the Wilson plot (Wilson, 1942), $B=7.3 \AA^{2}$, which is relatively low for a protein. After PHENIX refinement based on the spherical atom model, Fourier residual maps were computed to observe nonmodelled electron density on the covalent bonds using MoPro. A significant number of atoms in cholesterol oxidase have $B_{\text {eq }}$ factors as low as 4-7 $\AA^{2}$. After refinement using all reflections, the Fourier residual map rarely reveals the nonmodelled

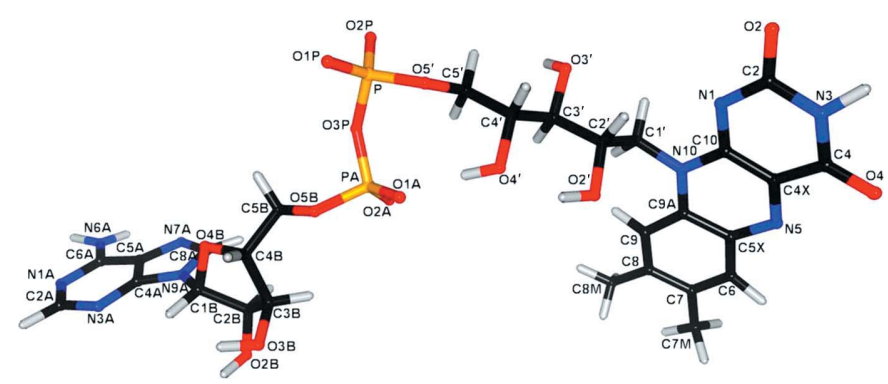

Figure 3

Ball-and-stick model of the FAD cofactor shown with the atomnumbering scheme for non-H atoms.

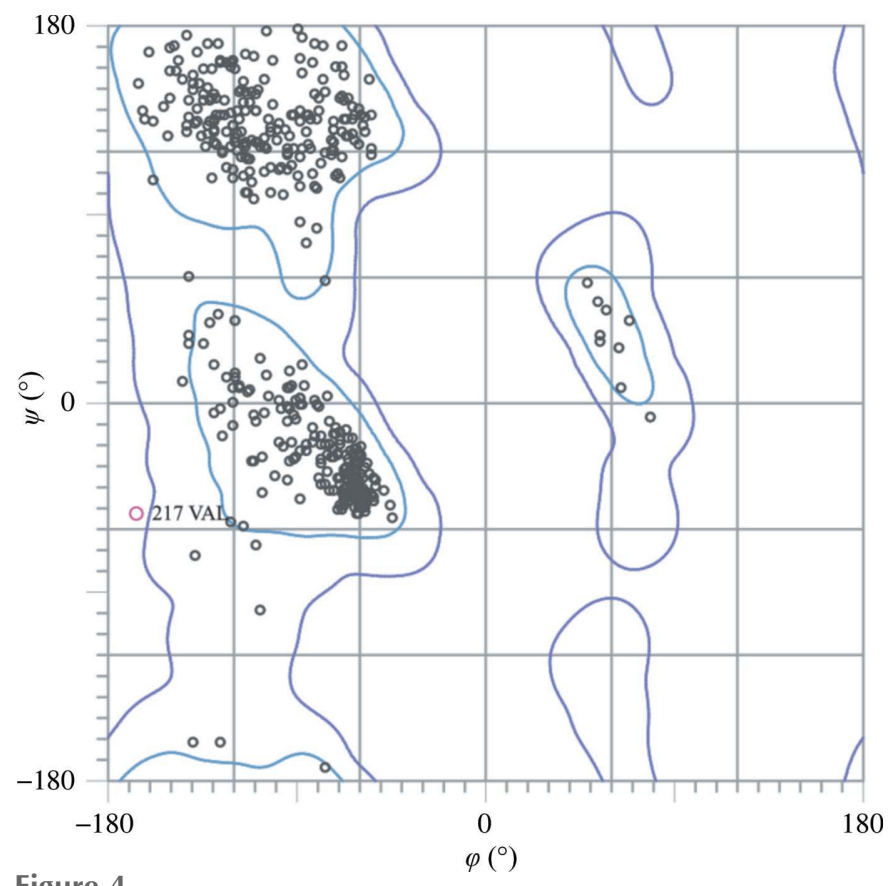

Figure 4

Ramachandran plot of the refined ChOx protein structure. 
deformation density on covalent bonds. For a few residues with the lowest thermal motion some of the bonding peaks may appear, but they are at the level of random noise (Fig. 6). Bonding electron-density peaks were clearly visible in several protein structures at ultrahigh or atomic resolution: a scorpion toxin at $0.96 \AA$ (Housset et al., 2000; Afonine et al., 2007), crambin at $0.54 \AA$ (Jelsch et al., 2000), RD1 antifreeze protein at $0.62 \AA$ (Afonine et al., 2004), trypsin at $0.8 \AA$ (Schmidt et al., 2003; Afonine et al., 2004), phospholipase at $0.8 \AA$ (Liu et al., 2003; Afonine et al., 2007) and human aldose reductase at $0.66 \AA$ (Guillot et al., 2008). The application of high-order refinement, where only the subatomic resolution reflections are used (typically $d<0.7 \AA$ ), permits one to highlight the remaining bonding density (Hansen \& Coppens, 1978) in Fourier maps computed using only the lower resolution reflections.

To decrease the noise in Fourier residual maps and to highlight the presence of possible bonding deformation density, average maps were also computed in the peptide-bond planes. The peptide moieties were sorted according to increasing $B_{\text {eq }}$ factors on the $\mathrm{O}$ atom and the maps were averaged over samples of 40 successive peptides. Regrouping the maps by the magnitude of the $B_{\text {eq }}$ factors enables the discrepancy in thermal motion between the different maps averaged to be limited. Such averaging of the residual electron density along the polypeptide backbone was performed on crambin at $0.54 \AA$ resolution and resulted in significant bonding density (Jelsch et al., 2000). However, bonding features were also visible on individual covalent bonds in the Fourier maps in the case of crambin.

The bonding density is clearly visible in the average map, with the lowest $B_{\text {eq }}$ factors on the $\mathrm{C}=\mathrm{O}, \mathrm{C}-\mathrm{C}^{\alpha}$ and $\mathrm{C}-\mathrm{N}$ bonds. The maps (Fig. 7) show decreasing bonding density as the thermal motion increases.

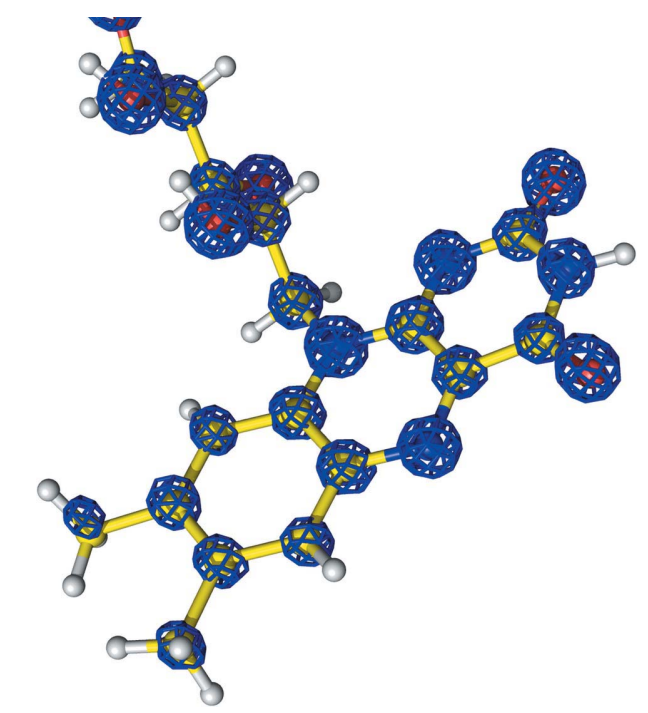

Figure 5

$2 F_{\mathrm{o}}-F_{\mathrm{c}}$ electron density on the isoalloxazine ring system of the flavin cofactor at the $5 \sigma$ level. The electron density shown at the high sigma level is generated mostly by the core electron shell located near the nuclei. The ellipsoidal shapes of the density therefore provide a picture of the anisotropic thermal motion of the atoms.
In a helical pseudo-octapeptide, it was observed that the Fourier residual bonding electron density is poorer towards the extremity of a phenyl side chain owing to increased thermal motion (Jelsch et al., 1998). Such results are also generally observed in small molecules at ultrahigh resolution, where the atoms with larger thermal motion $\left(B_{\text {eq }}>2 \AA^{2}\right)$ show poor and attenuated residual electron density on the covalent bonds and lone pairs. Therefore, comparison of residual electron densities for the same chemical group in different environments of a small molecule has to be carried out with care, as thermal motion effects can be much larger than the polarization itself. The refined static electron densities are also of poor quality when the thermal motion of atoms is higher than $B_{\text {eq }}=2 \AA^{2}$ and do not enable the observation of polarization differences. In protein structures, the thermal motion is too high to enable the refinement of individual atomic electron-density parameters. When the electron density is obtained from ELMAM2 database transfer, an average atom polarization is applied.

\subsection{Electrostatic potential}

The electrostatic potential (ESP) derived from the multipolar atom database ELMAM2 (Domagała et al., 2011) was computed at the interacting surface of the $\mathrm{ChOx}$ protein and the FAD ligand. Such database transfer necessitates the modelling of all $\mathrm{H}$ atoms of the molecular structure.

The ESP mapped over the FAD molecule surface is shown in Fig. 8(a). The FAD prosthetic group generates an overall negative electrostatic potential that complements a mainly positive potential on the inner cavity of the protein surface (Figs. $8 b$ and $8 c$ ). The total charge on the selected protein region obtained after database transfer was $+2.3 \mathrm{e}$, which complements the -2.0 e charge on the FAD molecule well. The two multipolar ESPs generated by the protein and by the FAD show a nice complementarity, which can be seen in Fig. 8.

The ESP generated by $A M B E R 03$ (Case et al., 2008) point charges was also computed and is shown in Fig. $8(c)$. The correlation coefficient between the ELMAM2 and AMBER03 ESP values on the molecular surface is relatively low at 0.05 , but the two ESPs show qualitatively similar features in Fig. 8. The average $A M B E R$ ESP on the FAD molecular surface is -0.03 e $\AA^{-1}$, while the average ELMAM2 ESP is 0.32 e $\AA^{-1}$. This is owing in part to a different global charge of the residues located within $5 \AA$ of the FAD cofactor: +1.0 e for

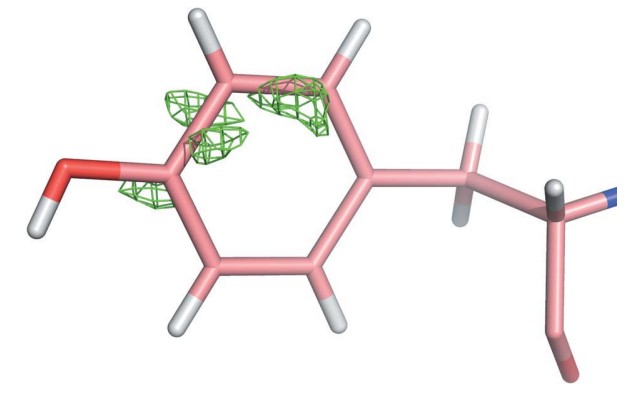

Figure 6

Residual Fourier map on residue Tyr195 drawn at the $2 \sigma$ contour level. 
$A M B E R$ and $+2.3 \mathrm{e}$ for ELMAM2. In addition, an ESP derived from the total electron density surrounding the nuclei is, by definition, more positive than that generated by point charges: for example, a spherical neutral atom generates a positive potential in space, while a point-charge model yields a zero potential.

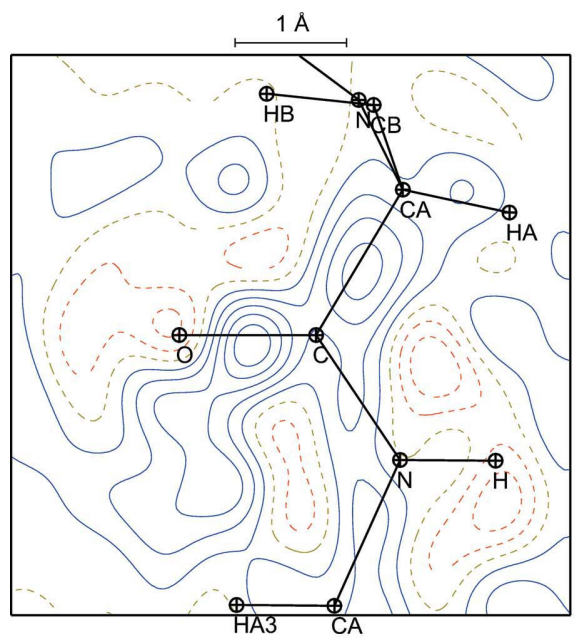

$(a)$

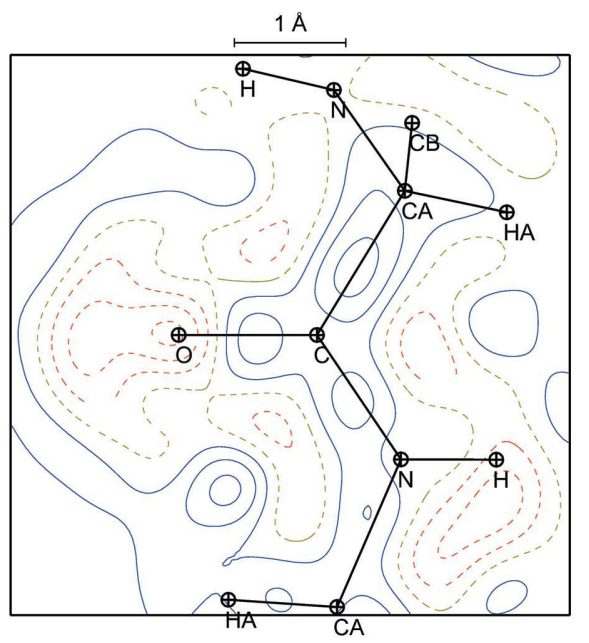

(b)

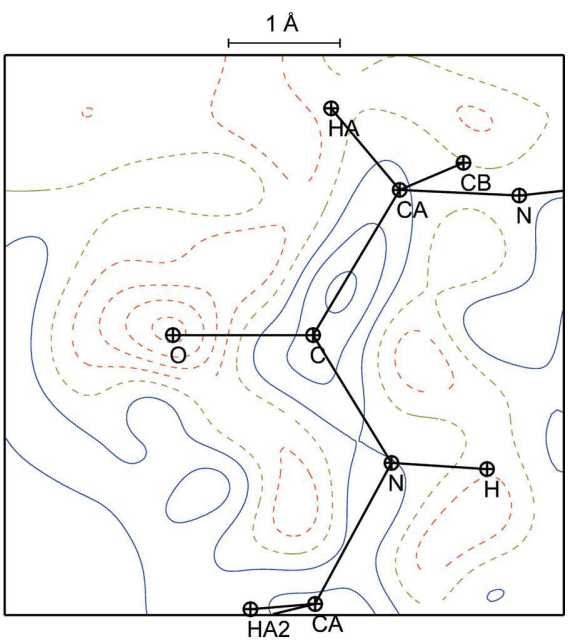

(c)

Figure 7

Average $F_{\mathrm{o}}-F_{\mathrm{c}}$ residual electron-density maps in the peptide-bond plane. (a) The 40 residues with lowest $B_{\mathrm{eq}}$ factor on the carbonyl $\mathrm{O}$ atom. Average $B_{\text {eq }}=5.73 \AA^{2}, B_{\text {min }}=5.1 \AA^{2}, B_{\max }=6.0 \AA^{2}$. (b) The 40 next residues with a higher $B$ factor. Average $B_{\text {eq }}=6.2 \AA^{2}, B_{\min }=6.0 \AA^{2}, B_{\max }=6.4 \AA^{2} .(c) 40$ residues with a $B$ factor between $B_{\min }=7.4 \AA^{2}$ and $B_{\max }=7.8 \AA^{2}$ (from the 161 st to the 200th residues with $B$ factors in ascending order), average $B_{\text {eq }}=$ $7.6 \AA^{2}$. Contour levels are at $\pm 0.02 \mathrm{e} \AA^{-3}$. Positive densities are shown as blue solid lines and negative densities are shown as red dashed lines. All maps were computed with the $\mathrm{O}$ atom at the origin; the carbonyl $\mathrm{C}$ atom defines the $x$ direction and the map plane is defined by the triplet $(\mathrm{O}, \mathrm{C}, \mathrm{N})$. Only the $\mathrm{O}$ atoms are strictly superposed in the different maps. No geometric compensation was applied to the maps to obtain perfect superposition for the $\mathrm{C}$ and $\mathrm{N}$ atoms. The geometric deviations are small within the peptide moiety ( $0.01 \AA$ for $\mathrm{C}$ atoms, for instance).

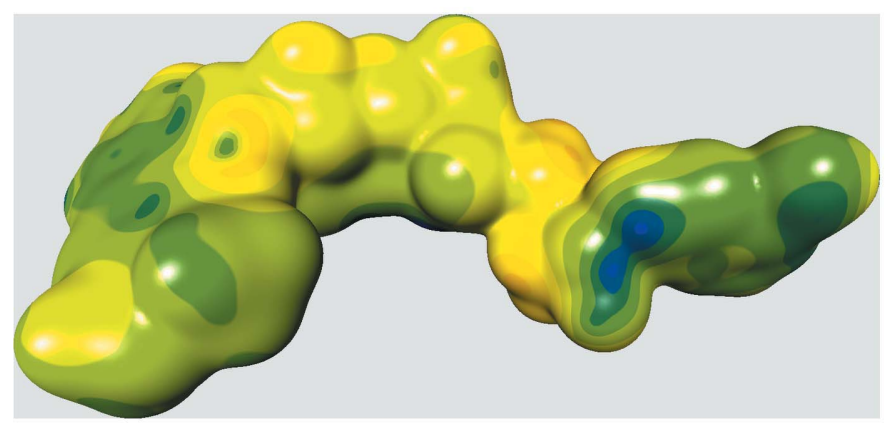

(a)

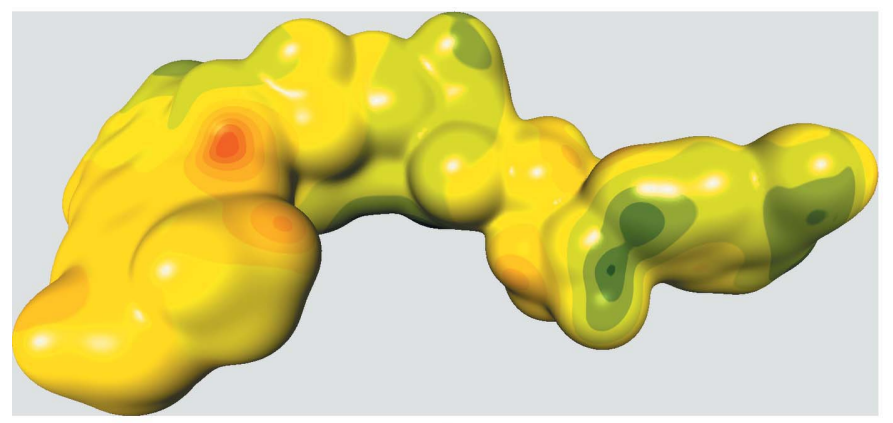

(b)
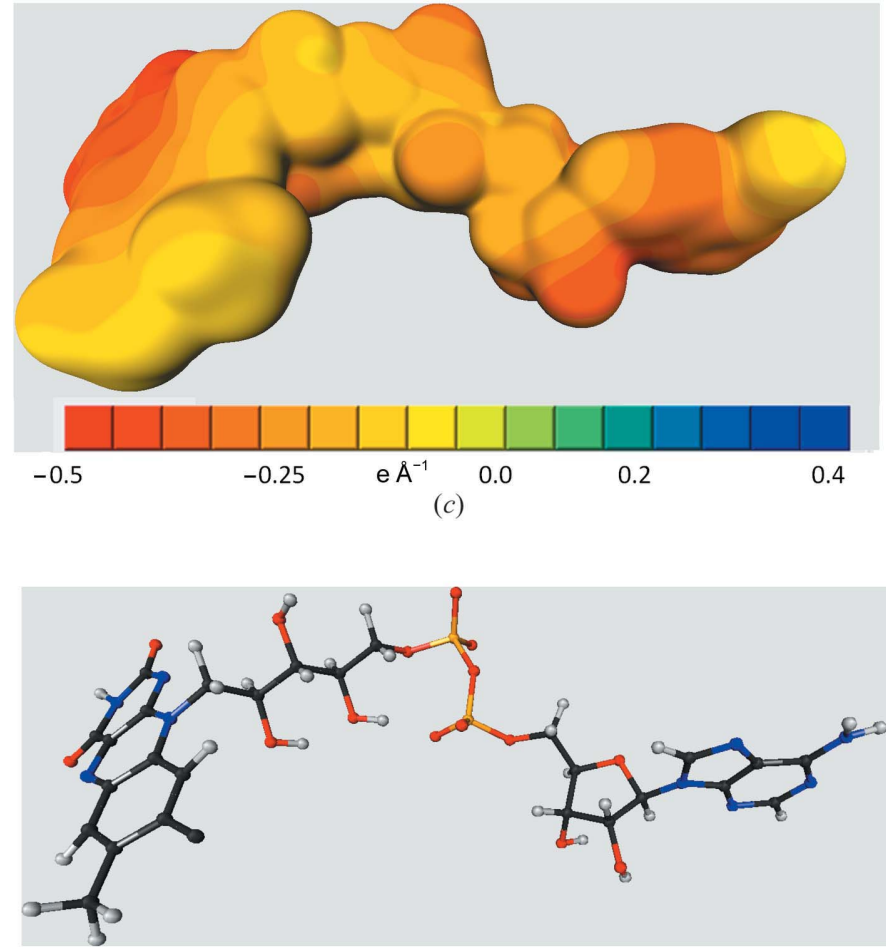

$(d)$

Figure 8

View of the FAD molecular surface coloured according to the electrostatic potential (ESP). (a) ESP derived from an ELMAM2 multipolar model generated by the protein active-site residues (all residues but FAD with an atom adjacent within $5 \AA$ to the FAD molecule were selected). (b) The same as $(a)$ but derived from $A M B E R 03$ point charges. (c) ELMAM2 ESP generated by the FAD cofactor. $(d)$ Orientation of the FAD cofactor. In $(a)$, $(b)$ and (c), ESP is mapped onto the $0.01 \mathrm{e} \AA^{-3}$ total electron-density isosurface. 
Table 2

Topological properties at the CPs of the interactions between the protein and the FAD ligand.

$d_{12}$ is the distance between the two atoms, $\rho\left(\mathbf{r}_{\mathrm{cp}}\right)$ is the electron density at the critical point and $\nabla^{2} \rho\left(\mathbf{r}_{\mathrm{cp}}\right)$ is the Laplacian. Only the strongest hydrogen bonds $\left(D_{\mathrm{e}} \geq\right.$ $20 \mathrm{~kJ} \mathrm{~mol}^{-1}$ ) are shown; the whole list is given in the Supporting Information. $G^{\mathrm{cp}}, V^{\mathrm{cp}}$ and $E^{\mathrm{cp}}$ are the kinetic, potential and total electronic energies (Abramov, 1997 ) at the critical point, respectively; $D_{\mathrm{e}}$ is the estimated dissociation energy (Espinosa \& Molins, 2000). Angle relates to the $\angle D-\mathrm{H} \cdots A$ angle value, where is $D$ and $A$ are the donor and acceptor atoms, respectively.

\begin{tabular}{|c|c|c|c|c|c|c|c|c|c|c|}
\hline Residue No. & Protein & FAD & $d_{12}(\AA)$ & Angle $\left(^{\circ}\right)$ & $\begin{array}{l}\rho\left(\mathbf{r}_{\mathrm{cp}}\right) \\
\left(\mathrm{e} \AA^{-3}\right)\end{array}$ & $\begin{array}{l}\nabla^{2} \rho\left(\mathbf{r}_{\mathrm{cp}}\right) \\
\left(\mathrm{e} \AA^{-5}\right)\end{array}$ & $\begin{array}{l}G^{\mathrm{cp}} \\
\left(\mathrm{kJ} \mathrm{mol}^{-1} \mathrm{bohr}^{-3}\right)\end{array}$ & $\begin{array}{l}V^{\mathrm{cp}} \\
\left(\mathrm{kJ} \mathrm{mol}^{-1} \mathrm{bohr}^{-3}\right)\end{array}$ & $\begin{array}{l}E^{\mathrm{cp}} \\
\left(\mathrm{kJ} \mathrm{mol}^{-1} \mathrm{bohr}^{-3}\right)\end{array}$ & $\begin{array}{l}D_{\mathrm{e}} \\
\left(\mathrm{kJ} \mathrm{mol}^{-1}\right)\end{array}$ \\
\hline Glu40 & OE2 & $\mathrm{HO} 2 \mathrm{~A}-\mathrm{O}$ & 1.76 & 172.5 & 0.300 & 1.2 & 64 & -99 & -35 & 49 \\
\hline Phe487 & $\mathrm{N}-\mathrm{H}$ & $\mathrm{O} 2$ & 1.90 & 174.5 & 0.226 & 1.8 & 59 & -97 & -38 & 49 \\
\hline Glu40 & OE1 & $\mathrm{HO} 3 \mathrm{~A}-\mathrm{O}$ & 1.84 & 162.9 & 0.250 & 1.3 & 54 & -84 & -30 & 42 \\
\hline Gly115 & $\mathrm{N}-\mathrm{H}$ & O1A & 1.99 & 170.0 & 0.184 & 1.5 & 46 & -75 & -29 & 38 \\
\hline Gly475 & $\mathrm{N}-\mathrm{H}$ & $\mathrm{O} 2 \mathrm{P}$ & 2.00 & 169.8 & 0.178 & 1.5 & 45 & -73 & -28 & 36 \\
\hline Met122 & $\mathrm{N}-\mathrm{H}$ & $\mathrm{O} 4$ & 2.10 & 161.2 & 0.142 & 1.4 & 73 & -60 & -23 & 30 \\
\hline Val250 & $\mathrm{N}-\mathrm{H}$ & $\mathrm{N} 1 \mathrm{~A}$ & 2.24 & 153.5 & 0.125 & 1.1 & 30 & -48 & -18 & 24 \\
\hline Asn119 & $\mathrm{N}-\mathrm{HD} 22$ & $\mathrm{O} 2^{\prime}$ & 2.20 & 171.5 & 0.108 & 1.1 & 27 & -43 & -16 & 22 \\
\hline Asn119 & $\mathrm{C}-\mathrm{HB} 2$ & N5 & 2.38 & 155.5 & 0.099 & 1.1 & 26 & -43 & -17 & 21 \\
\hline
\end{tabular}

\subsection{Topological analysis of FAD-protein hydrogen bonds}

The presence of intermolecular interactions can be accurately quantified by performing a topological analysis of electron-density distributions based on the quantum theory of atoms in molecules (QTAIM) approach (Bader, 1991). The presence of a $(3,-1)$ saddle critical point $(\mathrm{CP})$ along with a bond path between the two atoms is an indication of the presence of an interaction. This approach is extensively used to quantify intermolecular interactions in small-molecular systems (Mallinson et al., 2003; Munshi \& Row, 2005). The CPs, like the electrostatic potential, can be calculated on the basis of the transferred electron-density parameters. Abramov (1997) has proposed the evaluation of the local electronic kinetic energy density $G\left(\mathbf{r}_{\mathrm{cp}}\right)$ (in $\mathrm{kJ} \mathrm{mol}^{-1} \mathrm{bohr}^{-3}$ ) from the total electron density $\rho\left(\mathbf{r}_{\mathrm{cp}}\right)$ at the CPs of closed-shell interactions,

$$
G\left(\mathbf{r}_{\mathrm{cp}}\right)=\frac{3}{10}\left(3 \pi^{2}\right)^{2 / 3} \rho^{5 / 3}\left(\mathbf{r}_{\mathrm{cp}}\right)+\frac{1}{6} \nabla^{2} \rho\left(\mathbf{r}_{\mathrm{cp}}\right) .
$$

The local form of the virial theorem relates the Laplacian to both the local electronic kinetic energy density $G\left(\mathbf{r}_{\mathrm{cp}}\right)$ and the local electronic potential energy density $V\left(\mathbf{r}_{\mathrm{cp}}\right)$ (Bader, 1991; Espinosa \& Molins, 2000),

$$
V\left(\mathbf{r}_{\mathrm{cp}}\right)=\frac{1}{4} \nabla^{2} \rho\left(\mathbf{r}_{\mathrm{cp}}\right)-2 G\left(\mathbf{r}_{\mathrm{cp}}\right) .
$$

The estimated values of the interaction dissociation energies $D_{\mathrm{e}}\left(\right.$ in $\mathrm{kJ} \mathrm{mol}^{-1}$ ) can be obtained from the properties at the CPs (Espinosa \& Molins, 2000) using the equation

$$
D_{\mathrm{e}}=-\frac{1}{2} a_{\mathrm{o}}^{3} V_{\mathrm{cp}}
$$

where $a_{0}$ is the Bohr radius and $V_{\mathrm{cp}}$ is the value of the potential energy density at the CP (Espinosa \& Molins, 2000).

In total, the FAD cofactor forms 66 intermolecular interactions with the active-site resides of the protein. All of these interactions along with their topological properties are tabulated in Supplementary Table S1 and the most relevant (strongest) interactions are shown in Table 2. The contacts include $\mathrm{C}-\mathrm{H} \cdots \mathrm{O}, \mathrm{C}-\mathrm{H} \cdots \pi, \mathrm{N}-\mathrm{H} \cdots \mathrm{O}, \mathrm{O}-\mathrm{H} \cdots \mathrm{O}, \mathrm{N}-$ $\mathrm{H} \cdots \mathrm{N}$ and $\mathrm{H} \cdots \mathrm{H}$ interactions. FAD atoms $\mathrm{O}^{\prime}, \mathrm{O}^{\prime}, \mathrm{O}^{\prime}$ and O1A form linear hydrogen bonds, while the O5B, O4B, O4, $\mathrm{O} 2$ ', $\mathrm{O} 2$ and $\mathrm{O} 1 \mathrm{P}$ atoms form bifurcated hydrogen bonds to neighbouring residues. The $\mathrm{O} 3 \mathrm{~B}$ atom is trifurcated and the $\mathrm{O} 2 \mathrm{P}$ and $\mathrm{O} 2 \mathrm{~B}$ atoms each form four hydrogen bonds. The interactions are found to be directional in nature and generally point towards the electron lone-pair regions of the $\mathrm{O}$ atoms. All of the $\mathrm{N}$ atoms of FAD, except for N3 and N9A, participate in intermolecular interactions with the surrounding residues. The N1A atom is a trifurcated acceptor and the N3A atom is a bifurcated acceptor, while the N1, N5, N6A, N7A and N10 atoms each form a unique hydrogen bond.

Residues forming strong interactions with the FAD molecule are shown in Fig. 9. Val250 forms two strong hydrogen bonds to FAD; namely $\mathrm{N} 6 \mathrm{~A}-\mathrm{H} 61 \mathrm{~A} \cdots \mathrm{O}=\mathrm{C}$ and $\mathrm{N}-$ $\mathrm{H} \cdot \mathrm{N} 1 \mathrm{~A}$ bonds with estimated dissociation energies of 29 and $24 \mathrm{~kJ} \mathrm{~mol}^{-1}$, respectively (Table 2).

The carboxylate OE1 and OE2 atoms of Glu40 form two $\mathrm{O} \cdot \mathrm{H}-\mathrm{H}$-type hydrogen bonds to two sugar hydroxyl groups (HO3A and HO2A) of the FAD ligand. The resulting double $\mathrm{O}^{-} \cdots \mathrm{H}-\mathrm{O}$ interaction pattern can be identified as a synthon. These hydrogen bonds are almost linear (straight $\mathrm{O}-\mathrm{H} \cdots \mathrm{O}$ angle). The corresponding dissociation energies are 49 and $42 \mathrm{~kJ} \mathrm{~mol}^{-1}$, respectively. For reference, the dissociation energy for the $\mathrm{O}-\mathrm{H} \cdots \mathrm{O}^{-}$interaction was estimated to be in the range $60-120 \mathrm{~kJ} \mathrm{~mol}^{-1}$ as reported by Meot-Ner \& Sieck (1986). These interactions belong to the four strongest $\left(D_{\mathrm{e}}>\right.$ $40 \mathrm{~kJ} \mathrm{~mol}^{-1}$ ) hydrogen bonds between the protein and the FAD molecule.

Additionally, Gly114 also binds to the O3A atom. This $\mathrm{CA}-\mathrm{HA} 2 \cdots \mathrm{O} 3 \mathrm{~B}$ contact is only a 'weak' $\mathrm{C}-\mathrm{H} \cdots \mathrm{O}$ hydrogen bond, for which the interaction energy is normally in the range $4-10 \mathrm{~kJ} \mathrm{~mol}^{-1}$ (Desiraju, 1991). The estimated dissociation energy is high $\left(25 \mathrm{~kJ} \mathrm{~mol}^{-1}\right)$ and the contact distance of $2.34 \AA$ is well below the sum of van der Waals radii $\left(r_{\mathrm{O}}+r_{\mathrm{H}}=1.52+1.2=2.72 \AA\right.$; Bondi, 1964), indicating that the 
interaction is strongly involved in the anchoring of the FAD molecule in the active site.

Gly115 and Gly475 each form nearly linear strong $\mathrm{N}-$ $\mathrm{H} \cdots \mathrm{O}$ hydrogen bonds $\left(\angle \mathrm{N}-\mathrm{H} \cdots \mathrm{O} \simeq 170^{\circ}\right)$ to the $\mathrm{O} 3 \mathrm{~B}$, $\mathrm{O} 1 \mathrm{~A}$ and $\mathrm{O} 2 \mathrm{P}$ atoms of $\mathrm{FAD}$, respectively, and the $\mathrm{H} \cdots \mathrm{O}$ distances are short. The dissociation energies are quite high $\left(25,37\right.$ and $\left.36 \mathrm{~kJ} \mathrm{~mol}^{-1}\right)$, as the energy of hydrogen bonds between neutral moieties varies over a wide range from less than $4 \mathrm{~kJ} \mathrm{~mol}^{-1}$ to greater than $35 \mathrm{~kJ} \mathrm{~mol}^{-1}$ (Subramanian \& Zaworotko, 1994). These hydrogen bonds play a key role in the conformation of the bound FAD molecule as they are connected to the phosphate moiety.

From a chemical point of view, the important part of the FAD molecule is the isoalloxazine three-ring system. This portion of the molecule plays a crucial role in the redox chemistry of the enzyme. The moiety is involved in four strong hydrogen bonds to Asn119 (one hydrogen bond), Met122 (two hydrogen bonds) and Phe487 (one hydrogen bond) (Figs. 9 and 10). The last three hydrogen bonds appear to strongly influence the deformation of the isoalloxazine moiety from its planar conformation.

An aliphatic hydrogen bond is formed between Asn119 (CB-HB2) and the N5 atom of the FAD. The dissociation

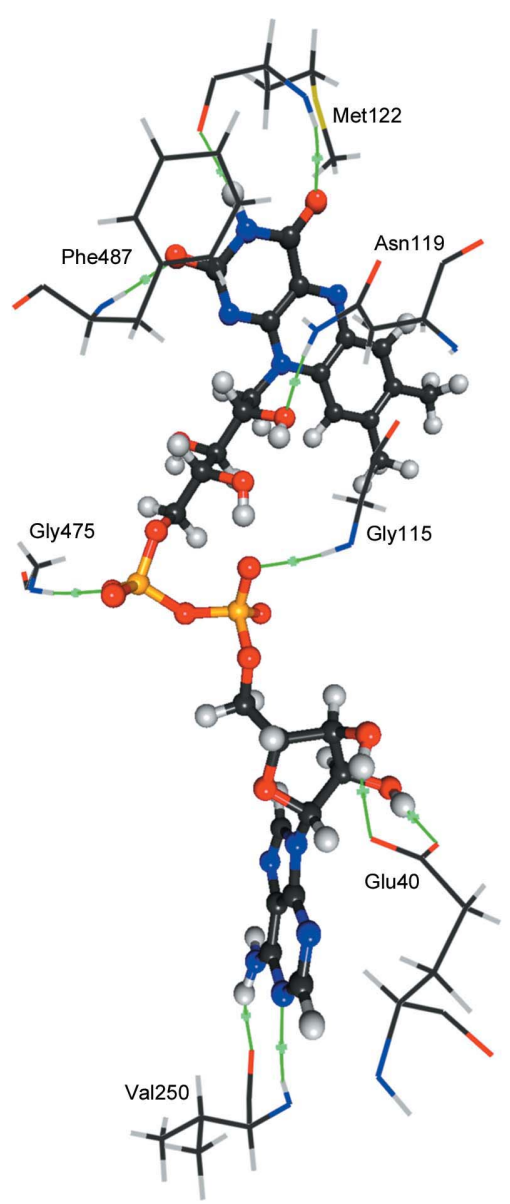

Figure 9

Stereographic view of the residues forming the strongest intermolecular interactions, in terms of the highest values of the dissociation energy at the CPs $\left(D_{\mathrm{e}} \geq 20 \mathrm{~kJ} \mathrm{~mol}^{-1}\right)$, with the cofactor FAD. The CPs are shown as green circles and the bond paths are shown in green. energy owing to this hydrogen bond is computed to be $21 \mathrm{~kJ} \mathrm{~mol}^{-1}$, which places this 'weak' $\mathrm{C}-\mathrm{H} \cdots \mathrm{O}$ interaction among the list of strongest hydrogen bonds. Nevertheless, this hydrogen bond involves the essential N5 atom of FAD, which is the site of electron transfer to the cofactor during the redox reaction.

The main chain (atoms $\mathrm{N}$ and $\mathrm{O}$ ) of Met122 forms two $\mathrm{N}-$ H...O-type hydrogen bonds to the FAD. In one case, the carbonyl $\mathrm{O}$ atom of Met122 acts as acceptor; in the other case, the $\mathrm{O} 4$ atom of FAD plays the role of acceptor.

In addition to influencing the geometry of the FAD isoalloxazine moiety, the energies and the involvement of backbone atoms in these hydrogen bonds cause a steric hindrance to residue Phe 487 . This residue has the only significantly deviating $\mathrm{C}^{\beta}$ position in the structure, $\delta=0.284 \AA$, based on analysis using MolProbity (Chen et al., 2010). Fig. 10 illustrates the theoretical ideal geometry (in red) of Phe487. If the sidechain geometry of Phe498 is regularized using Coot (Emsley et al., 2010), strong clashes occur with Met122 and Ala123 (distances between non-H atoms of less than $1.5 \AA$ ). Moreover, the main-chain $\mathrm{NH}$ group of Phe487 is also involved in a very short $\mathrm{N}-\mathrm{H}$... O hydrogen bond to the FAD isoalloxazine, displaying a short distance and an almost straight angle $\left(\mathrm{H} \cdots \mathrm{O} 2=1.90 \AA\right.$ and $\left.\angle \mathrm{N}-\mathrm{H} \cdots \mathrm{O} 2=174.7^{\circ}\right)$. The strength of this interaction results in a dissociation energy of $49 \mathrm{~kJ} \mathrm{~mol}^{-1}$.

The N-H...O hydrogen bond between the Asn119 side chain and the $\mathrm{O} 2^{\prime}$ atom of FAD is also worth mentioning as its dissociation energy is high $\left(22 \mathrm{~kJ} \mathrm{~mol}^{-1}\right)$ and the $\mathrm{N}-\mathrm{H} \cdots \mathrm{O}$ geometry is almost linear. All of the strongest hydrogen bonds shown in Table 2 have $\mathrm{H}$... O distances which are smaller by 0.34 to $0.96 \AA$ than the sum of van der Waals radii $(2.72 \AA)$.

The FAD molecule presents many internal conformational degrees of freedom. The FAD structure is significantly twisted within the cholesterol oxidase structure (Fig. 11) and its conformation is stabilized by both intramolecular hydrogen bonds and hydrogen bonds to the protein. Rotations around

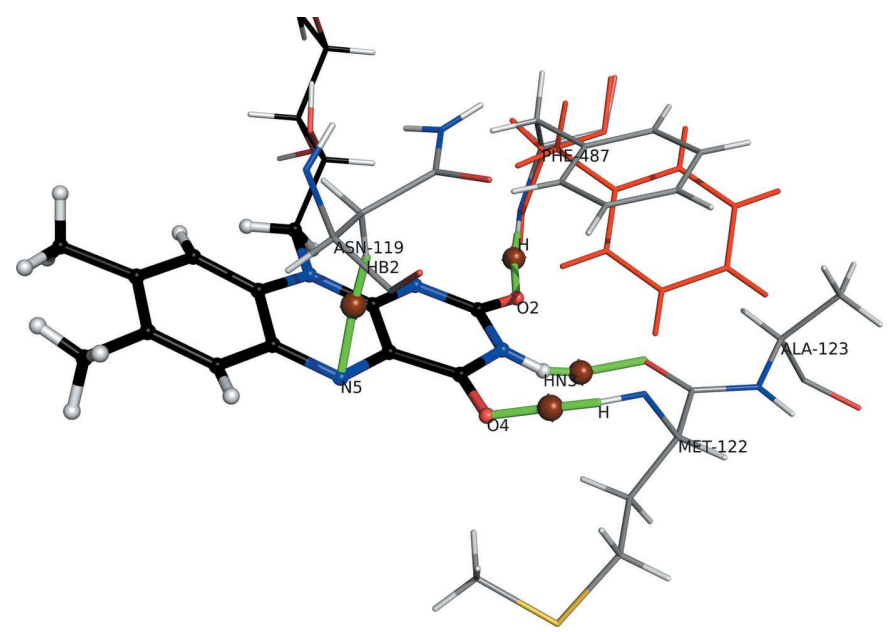

Figure 10

Residues forming the strongest intermolecular interactions with the FAD isoalloxazine moiety. The CPs are shown as brown spheres and the bond paths are shown in green. The theoretical ideal geometry of the Phe487 side chain is shown in red. 
covalent bonds involving the central pyrophosphate moiety lead to a FAD conformation in which the molecule forms a zigzag chain, with the pyrophosphate being oriented at almost $90^{\circ}$ with respect to the nucleotide long axis. While the protein active-site topology guides the conformation of the bound FAD ligand, a number of intramolecular interactions which further stabilize the folded conformation are observed.

\subsection{Stereochemistry of hydrogen bonds between main-chain} atoms

The $\mathrm{C}=\mathrm{O} \cdots \mathrm{H}-\mathrm{N}$-type interactions are the most common hydrogen bonds found in proteins and constitute an important driving force involved in the formation and stabilization of $\alpha$-helices and $\beta$-sheets (Chothia, 1984). They are of special importance for understanding protein structure, function, folding and stability (Bolen \& Rose, 2008). Moreover, hydrogen-bond analysis in protein three-dimensional structures provides essential information for modelling and protein structure prediction. Most hydrogen bonds in proteins are between main-chain atoms; an average proportion of $68 \%$ was reported by Stickle et al. (1992).

In this study, we focus on the $\mathrm{C}=\mathrm{O} \cdots \mathrm{H}-\mathrm{N}$ type of hydrogen bonds formed between main-chain atoms and quantify their conformational preferences within $\alpha$-helices, $\beta$-sheets and 'other' regions. The residues of the protein which are neither in an $\alpha$-helix nor in a $\beta$-sheet secondary structure are referred to as 'other'. $\mathrm{C}=\mathrm{O} \cdots \mathrm{H}-\mathrm{N}$-type interactions involving moieties in side chains such as, for instance, the amide group of Asn and Gln or NH groups in Trp, Arg or His are not considered. The stereochemistry of hydrogen bonds in proteins, including side chains, has been reviewed by Baker \& Hubbard (1984).

A total of 220 (117 in $\alpha$-helices, 42 in $\beta$-sheets and 61 'other') $\mathrm{N}-\mathrm{H} \cdots \mathrm{O}$ bonds are found in the protein structure. In $\alpha$-helices, hydrogen bonds occur typically between $\mathrm{N}-\mathrm{H}$ and $\mathrm{C}=\mathrm{O}$ groups separated by four amino acids. However, some additional hydrogen bonds occur in $\alpha$-helices between atoms separated by three residues. Therefore, within $\alpha$-helices, the hydrogen bonds have been divided into two subgroups: $i \rightarrow i+$ 3 (notated $i+3$ ) and $i \rightarrow i+4$ (notated $i+4)$, where $i$ refers to

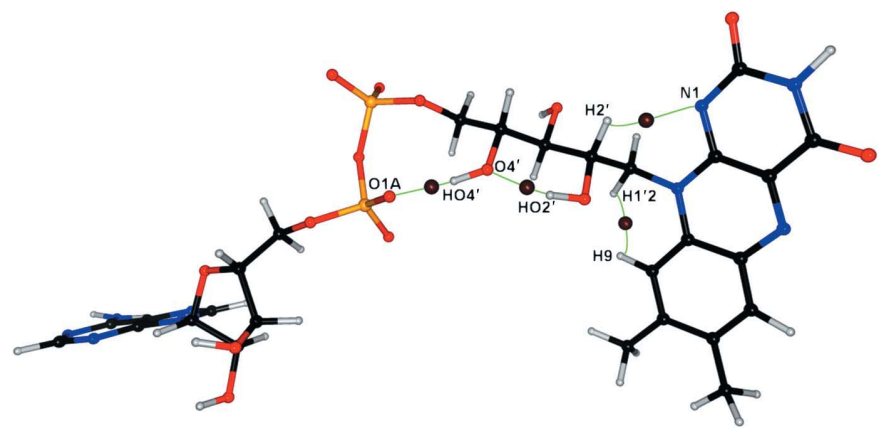

Figure 11

Conformation of the FAD cofactor in the ChOx binding site with internal hydrogen bonds shown. The CPs of hydrogen bonds are shown as brown spheres and the bond paths are shown in green. the residue number; the numbers of hydrogen bonds are 32 and 85 , respectively.

The statistical distribution of the occurrences of $\mathrm{O} \cdots \mathrm{H}$ distances in $\mathrm{C}=\mathrm{O} \cdots \mathrm{H}-\mathrm{N}$ hydrogen bonds for $\alpha$-helical, $\beta$-sheet and 'other' parts of the protein is depicted in Fig. 12. The average $\mathrm{O} \cdots \mathrm{H}$ distances are $2.11(2), 2.18(2)$ and 2.46 (3) $\AA$ in $\beta$-sheets and in $i+4$ and $i+3 \alpha$-helix hydrogen bonds, respectively. The number in parentheses is the uncertainty on the average value (r.m.s.d./ $N^{1 / 2}$ ). The corresponding standard deviations within the samples are $0.14,0.17$ and $0.19 \AA$, respectively. Statistically, hydrogen bonds have a tendency to be shorter within $\beta$-sheets compared with $\alpha$-helices and the distance distribution is also less spread out. The canonical $i+4$ hydrogen bonds within $\alpha$-helices are also significantly shorter than the $i+3$ hydrogen bonds. This is related to the generally less favourable hydrogen-bond directionality of $i+3$ hydrogen bonds, which form $\angle \mathrm{C}-$ $\mathrm{O} \cdots \mathrm{H}$ angles mostly between 114 and $90^{\circ}$. Another reason is that $i+3$ hydrogen bonds often occur in addition to $i+4$ hydrogen bonds in bifurcations and they have a tendancy to be sterically hindered. As observed in Fig. 12, the maximal frequency of $\mathrm{C}=\mathrm{O} \cdots \mathrm{H}-\mathrm{N}$ hydrogen bonds occurs for $d_{\mathrm{O}} \cdots \mathrm{H}$ distances around $2.0 \AA$ for $\beta$-sheet and $i+4$ hydrogen-bond types in $\alpha$-helices, while the peak is around $2.6 \AA$ for the $i+3$ type. The 'other' hydrogen bonds show average $\mathrm{O} \cdots \mathrm{H}$ distances of intermediate value, $\left\langle d_{\mathrm{O} \cdots \mathrm{H}}\right\rangle=2.20$ (3) $\AA$, with a similar spread of values (r.m.s.d. $=0.16 \AA$ ). In a study of six protein crystal structures at atomic resolution, Liebschner et al. (2011) found similar trends for $\mathrm{O} \cdots \mathrm{H}$ distances in $\alpha$-helices: 2.03 (16) and 2.22 (19) $\AA$ for $i+4$ and $i+3$ hydrogen bonds, respectively.

When the $\mathrm{O} \cdots \mathrm{N}$ distances are considered, the average values found are 2.92 (2) $\AA$ in $\beta$-sheets and 2.98 (2) and 3.11 (2) $\AA$ in $i+4$ and $i+3 \alpha$-helix hydrogen bonds, while the r.m.s.d. values are $0.12,0.14$ and $0.12 \AA$, respectively. These

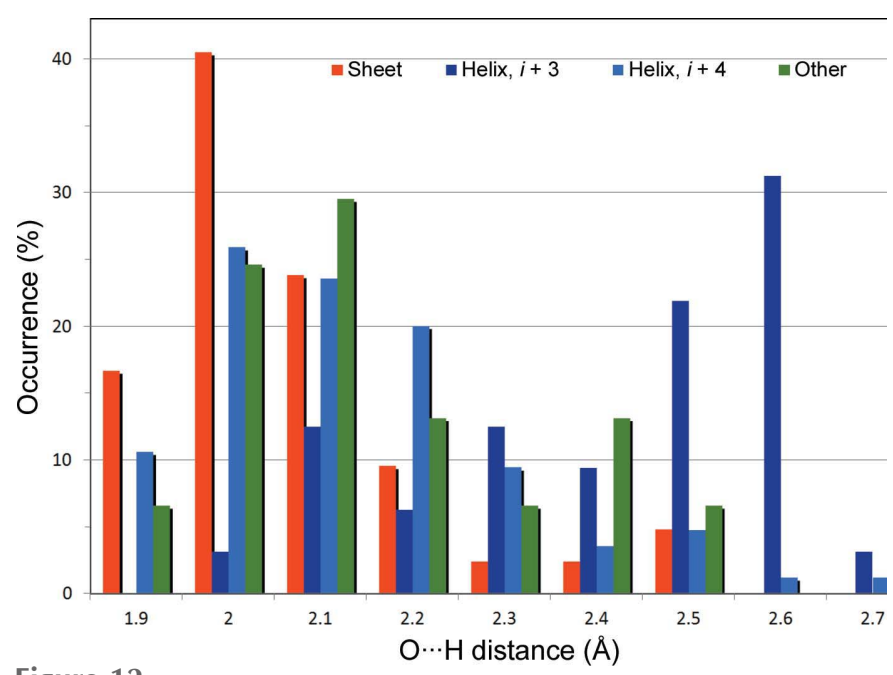

Figure 12

Occurrences of $\mathrm{O} \cdots \mathrm{H}$ distances in $\mathrm{C}=\mathrm{O} \cdots \mathrm{H}-\mathrm{N}$ hydrogen bonds for $\alpha$-helices, $\beta$-sheets and 'other' parts of the protein. Hydrogen bonds within $\alpha$-helices were subdivided into $i \rightarrow i+3$ and $i \rightarrow i+4$ interactions, where $i$ denotes the residue number. The helix/sheet/other classification refers to the $\mathrm{O}$ atom. 
distances are in accordance with those presented in a previous study (Koch et al., 2005), which showed that the mean hydrogen-bond length is $d_{\mathrm{ON}}=2.94$ (5) $\AA$ for parallel $\beta$-sheets and 2.94 (3) $\AA$ for antiparallel $\beta$-sheets and the mean $d_{\mathrm{ON}}$ value is 2.99 (2) $\AA$ for $\alpha$-helices, whereas the median $d_{\mathrm{ON}}$ values of Thomas et al. (2001) are $2.93 \AA$ for $\beta$-sheets and $3.00 \AA$ for $\alpha$-helices.

The second most characteristic feature of hydrogen bonds is their directionality, which can be analysed through precise descriptions of the $\angle \mathrm{C}=\mathrm{O} \cdots \mathrm{H}, \angle \mathrm{C}=\mathrm{O} \cdots \mathrm{N}$ and $\angle \mathrm{N}-$ $\mathrm{H} \cdot \mathrm{O}$ angles. Stereochemical analyses of hydrogen bonds in the crystals of small molecules are carried out using $\mathrm{H}$-atom positions. An experimental and theoretical charge-density analysis combined with a statistical survey of more than 500000 crystal structures revealed that hydrogen bonds show strong directionality towards the electron lone pairs of $\mathrm{O}$ atoms, especially in strong hydrogen bonds (Ahmed et al., 2013). Even fine differences in the positions of the lone pairs found between alcohol and phenol oxygen acceptors have been found to influence the position of donor $\mathrm{H}$ atoms.

In protein crystal structures at usual resolutions, $\mathrm{H}$ atoms are not visible in the electron-density maps; therefore, authors generally carry out stereochemical analyses on the $\mathrm{C}, \mathrm{O}$ and $\mathrm{N}$ atom positions (Koch et al., 2005; Thomas et al., 2001). In the present ultrahigh-resolution crystal structure of cholesterol oxidase, most of the $\mathrm{H}$ atoms in $\mathrm{NH}$ groups are visible in the electron-density maps. In other cases, the position of the amide $\mathrm{H}$ atom can be placed according to stereochemical rules such as the standard $\mathrm{N}-\mathrm{H}$ distance, which is known from neutron diffraction studies, and the assumption of a planar

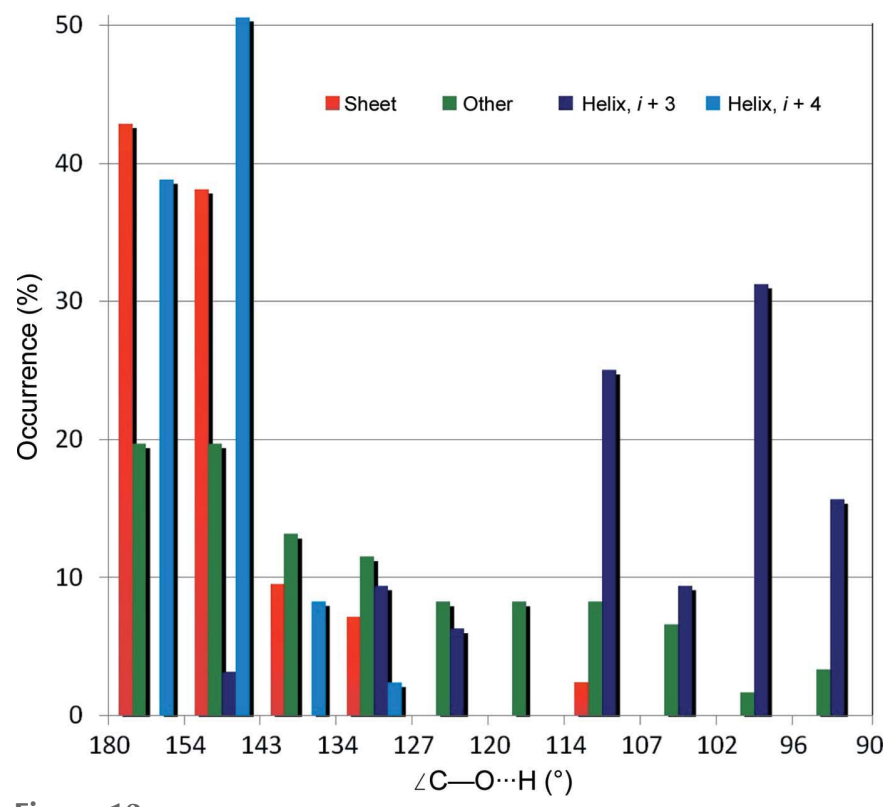

Figure 13

Percentages of hydrogen bonds found in $\alpha$-helices $(i \rightarrow i+3$ and $i \rightarrow i+4)$, $\beta$-sheets and 'other' parts of the protein in different intervals of $\angle \mathrm{C}=\mathrm{O} \cdots \mathrm{H}$. The hemisphere $\angle \mathrm{C}=\mathrm{O} \cdots \mathrm{H}=90-180^{\circ}$ was divided into $10^{\circ}$ intervals. The angle interval limits were at $90^{\circ}+\arccos (0.1), 90^{\circ}+$ $\arccos (0.2), \ldots, 90^{\circ}+\operatorname{arcos}(0.9)$ in order to have successive crowns with the same solid angle. The percentages are then representative of the frequency of hydrogen bonds in a given direction. peptide. In a survey of the peptide $\omega$ angles in the Cambridge Structural Database (CSD) of small molecules (Allen, 2002), MacArthur \& Thornton (1996) observed up to a $6^{\circ}$ deviation from planarity.

The angle distribution within $\mathrm{C}=\mathrm{O} \cdots \mathrm{H}-\mathrm{N}$ hydrogen bonds was therefore analysed (Figs. 13, 14 and 15) and revealed a number of discrepancies between the different secondary-structural elements. The most favoured regions for the $\mathrm{H}$-atom position in $\alpha$-helices and $\beta$-sheets is $154-180^{\circ}$ (Fig. 13), which does not correspond to the commonly accepted direction of the electron lone pairs $\left(120^{\circ}\right)$. Furthermore, this is not the favoured region in the crystal structures of small molecules; Wood et al. (2008) found that the most energetically favourable angles are in the range $127-140^{\circ}$. The average $\angle \mathrm{C}=\mathrm{O} \cdots \mathrm{H}$ angle for $\beta$-sheets is $151^{\circ}$ and is close to that found for $i+4$ hydrogen bonds in $\alpha$-helices $\left(151^{\circ}\right)$. By contrast, $i+3$ hydrogen bonds show their highest frequencies very far from the most energetically favourable $\angle \mathrm{C}=\mathrm{O} \cdots \mathrm{H}$ angles, with an average value of $107^{\circ}$. Two different maxima are clearly visible (Fig. 13) in the ranges $143-180$ and $90-114^{\circ}$ for $i+4$ and $i+3$ hydrogen bonds, respectively. Hydrogen bonds obey special geometric constraints in secondarystructure elements of proteins, which make them deviate from ideal geometry (Baker \& Hubbard, 1984). As $\alpha$-helices are known to be the most constrained backbone structures in peptides and proteins (Baker \& Hubbard, 1984), this result appears to be sensible. These results are comparable with those of the study of Liebschner et al. (2011), in which the average $\angle \mathrm{C}=\mathrm{O} \cdots \mathrm{H}$ value was found to be $149(8)$ and $110(11)^{\circ}$ for $i+4$ and $i+3$ hydrogen bonds in $\alpha$-helices, respectively.

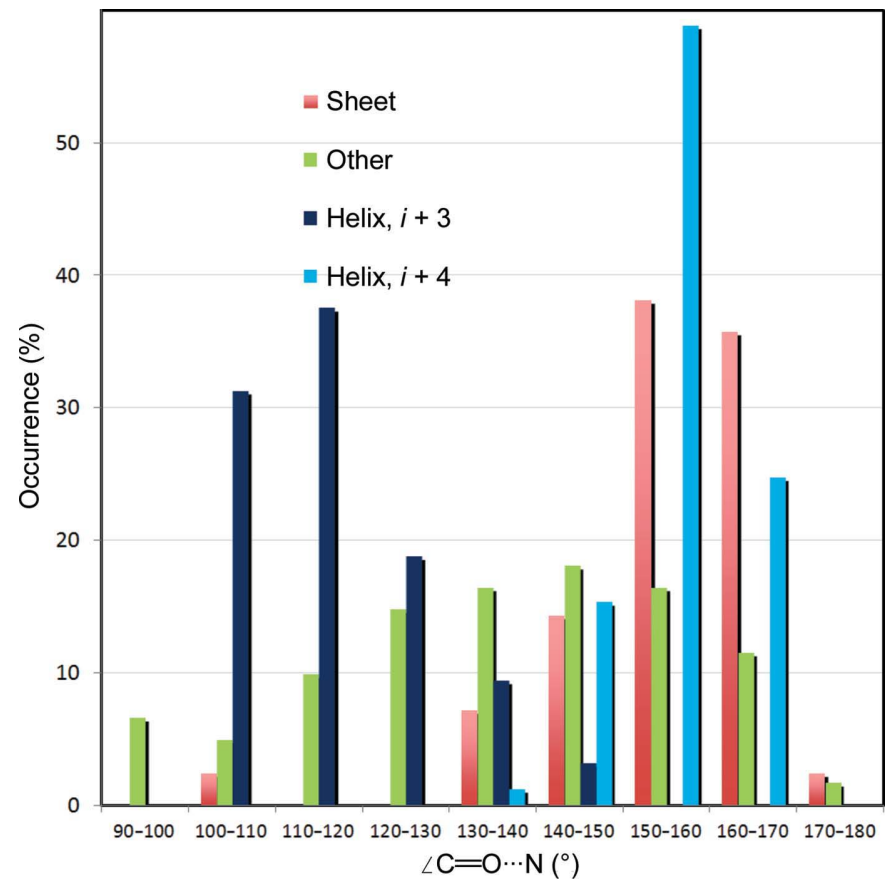

Figure 14

Percentage distribution of $\angle \mathrm{C}=\mathrm{O} \cdots \mathrm{N}$ as found in the $\mathrm{C}=\mathrm{O} \cdots \mathrm{H}-\mathrm{N}$ hydrogen bonds for $\alpha$-helices, $\beta$-sheets and 'other' parts of the cholesterol oxidase protein. 
Table 3

Average values of $\angle \mathrm{C}=\mathrm{O} \cdots \mathrm{H}$ and $\angle \mathrm{C}=\mathrm{O} \cdots \mathrm{N}$ angles in the secondarystructure elements.

The root-mean-square deviation for the samples is also given.

\begin{tabular}{|c|c|c|c|c|}
\hline \multirow[b]{2}{*}{$\begin{array}{l}\text { Secondary } \\
\text { structure }\end{array}$} & \multicolumn{2}{|c|}{$\angle \mathrm{C}=\mathrm{O} \cdots \mathrm{H}\left({ }^{\circ}\right)$} & \multicolumn{2}{|c|}{$\angle \mathrm{C}=\mathrm{O} \cdots \mathrm{N}\left({ }^{\circ}\right)$} \\
\hline & Mean (e.s.d.) & R.m.s.d. $(\AA)$ & Mean (e.s.d.) & R.m.s.d. $(\AA)$ \\
\hline $\begin{array}{l}\beta \text {-Sheet } \\
\alpha \text {-Helix }\end{array}$ & $151(2)$ & 12 & $154(2)$ & 12 \\
\hline$i+4$ & $151(1)$ & 7 & $155(1)$ & 6 \\
\hline$i+3$ & $107(2)$ & 14 & $115(1)$ & 9 \\
\hline Other & $134(3)$ & 20 & $136(3)$ & 21 \\
\hline
\end{tabular}

The conformations closest to the ideal angle values are realised for the 'other' hydrogen bonds, which are not involved in these secondary-structure elements. For 'other' hydrogen bonds, the average $\angle \mathrm{C}=\mathrm{O} \cdots \mathrm{H}$ value is $134^{\circ}$ and is the closest to the average angle of $139.0(8)^{\circ}$ found for $\mathrm{C}=\mathrm{O} \cdots \mathrm{H}-\mathrm{N}$ bonds in the CSD (Wood et al., 2008). In the statistical analysis of the CSD by Ahmed et al. (2013), it was found that for hydrogen bonds involving $\mathrm{C}=\mathrm{O}$ carbonyl moieties in organic molecules, the highest propensity of hydrogen localization was towards the oxygen electron lonepair directions and was close to the $s p^{2}$ hybridization plane. Occurrences within $\pm 13^{\circ}$ of the electron lone-pair direction at $120^{\circ}$ are however not frequent in ChOx, except for $i+3$ $\alpha$-helix hydrogen bonds. As shown in Fig. 13, the majority of $\angle \mathrm{C}=\mathrm{O} \cdots \mathrm{H}$ angles for $\beta$-sheet and canonical $i+4 \alpha$-helix hydrogen bonds are in the range $150-180^{\circ}$. The stereo-

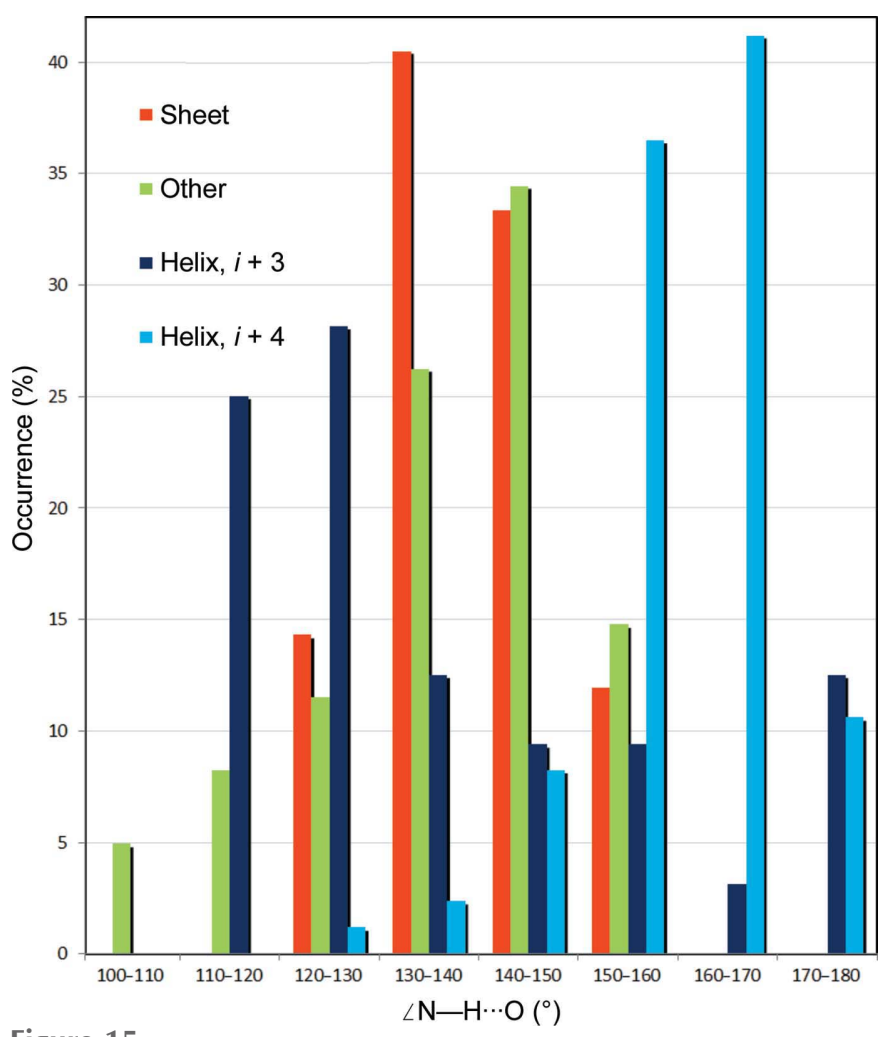

Figure 15

Percentage distribution of $\angle \mathrm{N}-\mathrm{H} \cdots \mathrm{O}$ as found in the $\mathrm{C}=\mathrm{O} \cdots \mathrm{H}-\mathrm{N}$ hydrogen bonds for $\alpha$-helices, $\beta$-sheets and 'other' parts of the ChOx protein. chemistry of hydrogen bonds in protein-ligand environments closely resembles that observed for small-molecule crystal structures, as verified by Klebe (1994). However, this is not the case for $\beta$-sheet and $i+4 \alpha$-helix main-chain hydrogen bonds, which are constrained by the global architecture of these secondary-structural elements.

The mean values of $\angle \mathrm{C}=\mathrm{O} \cdots \mathrm{N}$ are $155,115,154$ and $136^{\circ}$ for $i+4$ and $i+3 \alpha$-helix, $\beta$-sheet and 'other' hydrogen bonds respectively (Table 3, Fig. 14). The average angle for $i+3$ hydrogen bonds is the lowest and there are frequent occurrences only for low angles between 101 and $143^{\circ}$. As expected, the $i+4 \alpha$-helix hydrogen bonds mostly have directions close to linear for $\angle \mathrm{C}=\mathrm{O} \cdots \mathrm{N}$ (in the range $154-180^{\circ}$ ). As a consequence of the $\alpha$-helix geometry, the $\mathrm{C}=\mathrm{O}$ and $\mathrm{N}$ atoms are not far from having a linear geometry.

$\beta$-Sheets show similar $\angle \mathrm{C}=\mathrm{O} \cdots \mathrm{N}$ geometry as $i+4 \alpha$-helix hydrogen bonds. 'Other' hydrogen bonds have a much wider and flatter spectrum of angles; presumably, the distribution is based on the specific interactions rather than being constrained by the helical or sheet structure.

As the values $\angle \mathrm{C}=\mathrm{O} \cdots \mathrm{N}$ and $\angle \mathrm{C}=\mathrm{O} \cdots \mathrm{H}$ are partly correlated, some similar tendencies are found for the two angles analysed with respect to the four types of hydrogen bonds ( $i+3$ and $i+4 \alpha$-helix, $\beta$-sheet and other).

It has been well documented that $D-\mathrm{H} \cdots A$ (where is $D$ is a donor and $A$ is an acceptor) hydrogen-bonded interactions are believed to have a statistical preference for linearity based on database studies (Wood et al., 2008). The definitions of hydrogen bonds in the literature generally require $\angle D-$ $\mathrm{H} \cdots A$ angles larger than a given value (90-120 ; Arunan et al., 2011). The percentage distribution of $\angle \mathrm{N}-\mathrm{H} \cdots \mathrm{O}$ angles (Fig. 15) shows that the majority of hydrogen bonds of

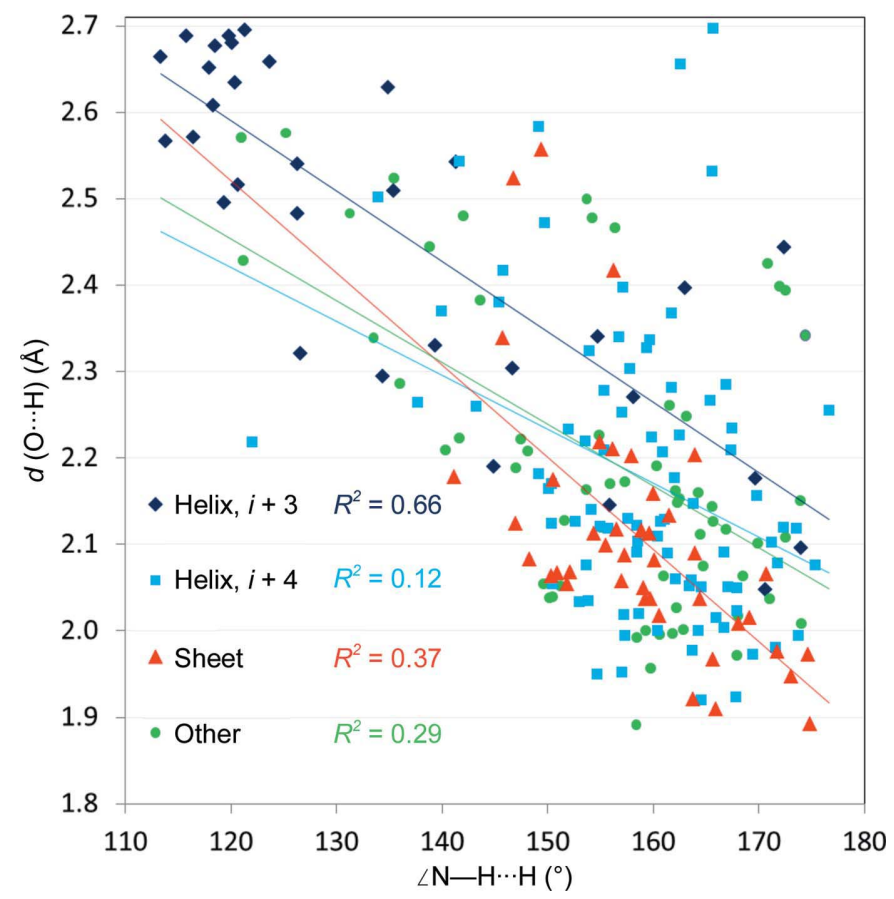

Figure 16

Scatterplot of $\angle \mathrm{N}-\mathrm{H} \cdots \mathrm{O}$ angles versus $\mathrm{H} \cdots \mathrm{O}$ distances. 
Table 4

Statistics for some covalent bonds in the ChOx protein.

Distances are divided into $\alpha$-helix $(i+3 / i+4), \beta$-sheet and 'other' categories. Bifurcated $(i+3, i+4)$ hydrogen bonds on the carbonyl acceptor were classified as $i+3$ hydrogen bonds. Disordered atoms of $\mathrm{ChOx}$ were excluded. $\mathrm{C}=\mathrm{O}$ and $\mathrm{C}-\mathrm{N}$ bond distances were excluded for $\mathrm{C}$ atoms with $B_{\text {eq }}>10 \AA^{2}$. Similarly, $\mathrm{C}^{\alpha}-\mathrm{C}$ and $\mathrm{C}^{\alpha}-\mathrm{N}$ bonds were excluded for $\mathrm{C}^{\alpha}$ atoms with $B_{\mathrm{eq}}>$ $10 \AA^{2}$. In the category 'All', only disordered atoms were excluded. The 'Jaskolski proteins' line refers to the study by Jaskolski et al. (2007) of very high resolution $d<0.8 \AA$ protein structures and atoms with $B<40 \AA^{2}$. The 'Jaskolski CSD' line refers to the same article in which bond lengths were collected from structures in the CSD with $R<5 \%$. The PHENIX target value is from the Engh \& Huber (1991) stereochemical dictionary, which was built using appropriate chemical fragments found in the CSD.

\begin{tabular}{|c|c|c|c|}
\hline Bond & No. & $\langle d\rangle$ (e.s.d.) $(\AA)$ & R.m.s.d. (ঐ) \\
\hline \multicolumn{4}{|l|}{$\mathrm{C}=\mathrm{O}$} \\
\hline Helix $i+4$ & 85 & $1.2378(9)$ & 0.009 \\
\hline Helix $i+3$ & 32 & $1.2415(17)$ & 0.010 \\
\hline Sheets & 42 & $1.2304(11)$ & 0.008 \\
\hline Other & 59 & $1.2334(13)$ & 0.010 \\
\hline All & 469 & $1.2338(5)$ & 0.010 \\
\hline PHENIX target & - & $1.231(20)$ & - \\
\hline Jaskolski proteins & - & 1.234 & 0.013 \\
\hline Jaskolski CSD & 480 & 1.231 & 0.009 \\
\hline \multicolumn{4}{|l|}{$\mathrm{C}-\mathrm{C}^{\alpha}$} \\
\hline Helix $i+4$ & 83 & $1.5258(8)$ & 0.008 \\
\hline Helix $i+3$ & 32 & $1.5242(17)$ & 0.010 \\
\hline Sheets & 40 & $1.5211(11)$ & 0.007 \\
\hline Other & 59 & $1.5247(10)$ & 0.008 \\
\hline All & 455 & $1.5233(4)$ & 0.008 \\
\hline PHENIX target & - & $1.525(21)$ & - \\
\hline Jaskolski proteins & - & 1.527 & 0.013 \\
\hline Jaskolski CSD & 146 & 1.523 & 0.011 \\
\hline \multicolumn{4}{|l|}{$\mathrm{C}-\mathrm{N}$} \\
\hline Helix $i+4$ & 85 & $1.3302(7)$ & 0.006 \\
\hline Helix $i+3$ & 32 & $1.3293(11)$ & 0.006 \\
\hline Sheets & 38 & $1.3312(9)$ & 0.006 \\
\hline Other & 59 & $1.3320(10)$ & 0.008 \\
\hline All & 459 & $1.3313(3)$ & 0.007 \\
\hline PHENIX target & - & $1.329(14)$ & - \\
\hline Jaskolski proteins & - & 1.334 & 0.013 \\
\hline Jaskolski CSD & 348 & 1.332 & 0.008 \\
\hline \multicolumn{4}{|l|}{$\mathrm{N}-\mathrm{C}^{\alpha}$} \\
\hline Helix $i+4$ & 83 & $1.4561(7)$ & 0.006 \\
\hline Helix $i+3$ & 32 & $1.4553(12)$ & 0.007 \\
\hline Sheets & 40 & $1.4534(11)$ & 0.007 \\
\hline Other & 59 & $1.4530(13)$ & 0.010 \\
\hline All & 457 & $1.4549(4)$ & 0.008 \\
\hline PHENIX target & - & $1.458(19)$ & - \\
\hline Jaskolski proteins & - & 1.454 & 0.012 \\
\hline Jaskolski CSD & 231 & 1.455 & 0.007 \\
\hline
\end{tabular}

cholesterol oxidase are not far from being straight (angle of $>154^{\circ}$ ). The average $\angle \mathrm{N}-\mathrm{H} \cdots \mathrm{O}$ values for $\beta$-sheets and $i+4$ $\alpha$-helices are not far from $180^{\circ}$ and are comparable at 158 (1) and $158(1)^{\circ}$, respectively, as a consequence of the geometry of these secondary-structure elements. 'Other' $\angle \mathrm{N}-\mathrm{H} \cdots \mathrm{O}$ angles reach a similar mean value of $156(2)^{\circ}$, while for $i+3$ $\alpha$-helices the value is much lower at $136(4)^{\circ}$.

Three of the four types of hydrogen bonds $(i+4 \alpha$-helix, $\beta$-sheet and other) show almost the same trend in the occurrence graph, with the only strong frequencies being at geometries $\angle \mathrm{N}-\mathrm{H} \cdots \mathrm{O} \simeq 180^{\circ}$. The $i+3 \alpha$-helix hydrogen bonds show a distinct behaviour and the geometry is not as directional as for the other types, as there are two maxima of occurrences around $\angle \mathrm{N}-\mathrm{H} \cdots \mathrm{O}$ angles of $180^{\circ}$ and $120^{\circ}$. The $i+3$ hydrogen bonds are bifurcated; they occur in addition to the canonical $i+4$ hydrogen bonds in $\alpha$-helices. The two oxygen acceptors in bifurcated hydrogen bonds must point in distinct directions; therefore, the additional $i+3$ hydrogen bonds are often required to have an $\angle \mathrm{N}-\mathrm{H} \cdots \mathrm{O}$ angle far from linearity.

Based on a statistical study of the Cambridge Structural Database (Allen, 2002) and $a b$ initio intermolecular interaction energy calculations, Wood et al. (2008) have analysed the geometry of $D-\mathrm{H} \cdots A$ interactions. Interactions with $D-\mathrm{H} \cdots A$ angles in the range $120-140^{\circ}$ are observed to have substantially reduced stabilization energies and angles below $120^{\circ}$ are generally unlikely to correspond to significant interactions.

$28 \%$ of the $i+3$ interactions (Fig. 15) have $D-\mathrm{H} \cdots A$ values lower than $120^{\circ}$ and were not considered as hydrogen bonds but rather as van der Waals interactions. The majority (54\%) of the $i+3$ interactions in $\alpha$-helices have $\angle \mathrm{N}-\mathrm{H} \cdots \mathrm{O}$ values lower than $127^{\circ}$; although these hydrogen bonds are polar, their presence is mostly a consequence of the local $\alpha$-helical structure arrangement with strong $i+4$ hydrogen bonds rather than a driving force. This is in accordance with Fig. 12, in which most of the $i+3$ hydrogen bonds show long $\mathrm{O} \cdots \mathrm{H}$ distances $(>2.5 \AA)$ at almost van der Waals contact distances (2.72 ̊).

The two-dimensional scatter plot of $\angle \mathrm{N}-\mathrm{H} \cdots \mathrm{O}$ angles versus $\mathrm{H}$... O distances (Fig. 16) shows a clear global relationship between distance and angle; the average $\mathrm{H} \cdots \mathrm{O}$ distance decreases as the $\angle \mathrm{N}-\mathrm{H} \cdots \mathrm{O}$ angle becomes closer to $180^{\circ}$. For all types of hydrogen bonds, there is a clear dependence between the two values, as previously observed by Wood et al. (2008) for small-molecule structures in the CSD. Strong hydrogen bonds with $d_{\mathrm{O} \ldots \mathrm{H}}<2.2 \AA$ are only found at $\angle \mathrm{N}-\mathrm{H} \cdots \mathrm{O}$ angles larger than $140^{\circ}$. The $\alpha$-helix $i+3$ hydrogen bonds show peculiar characteristics, with a large number of interactions occurring at large $\mathrm{H} \cdots \mathrm{O}$ distances and low $\angle \mathrm{N}-\mathrm{H} \cdots \mathrm{O}$ values in the range $110-130^{\circ}$. The linear fits show weak to moderate correlation between the $\angle \mathrm{N}-\mathrm{H} \cdots \mathrm{O}$ and $d_{\mathrm{O} \ldots \mathrm{H}}$ values, except for $\alpha$-helix $i+3$ interactions. The fitted linear curves of $d_{\mathrm{O}} \ldots \mathrm{H}$ versus $\angle \mathrm{N}-\mathrm{H} \cdots \mathrm{O}$ however still indicate that $\mathrm{H} \cdots \mathrm{O}$ distances have a tendency to be higher for $\alpha$-helix $i+3$ interactions compared with the other three types.

\subsection{Stereochemistry of main-chain bonds}

To analyse the source of differences in $\mathrm{C}=\mathrm{O}$ bond lengths, the structural dependences along the polypeptide main-chain of ChOx were investigated in the different secondarystructural elements. Bond lengths were restrained to the PHENIX target definitions of interatomic distances, with an allowed standard deviation of $0.02 \AA$. Deviations of distances from the target values were still observed as the diffraction data are at atomic resolution, and have been analyzed.

Table 4 shows the distribution of $\mathrm{C}=\mathrm{O}$ bond-length occurrences along with other statistical factors. The mean $\mathrm{C}=\mathrm{O}$ bond lengths for 'All' and 'Other' hydrogen bonds are similar and reflect the value of $1.234 \AA$ reported by Jaskolski et al. (2007) for very high resolution protein structures. In the 
case of aldose reductase, higher values of 1.236 (8) and 1.235 (9) $\AA$ were found using a multipolar and an aspherical atom model, respectively.

The bond length reported for the PHENIX target [1.231 (20) $\AA$ ], which originates from statistics on the CSD, is the same as that reported for the CSD study of Jaskolski et al. (2007). This value is slightly lower, but comparable within uncertainty, to that reported for the protein study of Jaskolski et al. (2007). The discrepancy was interpreted by Jaskolski and coworkers as reflecting the systematic involvement of the main-chain carbonyl groups of proteins in similar hydrogenbonding interactions.

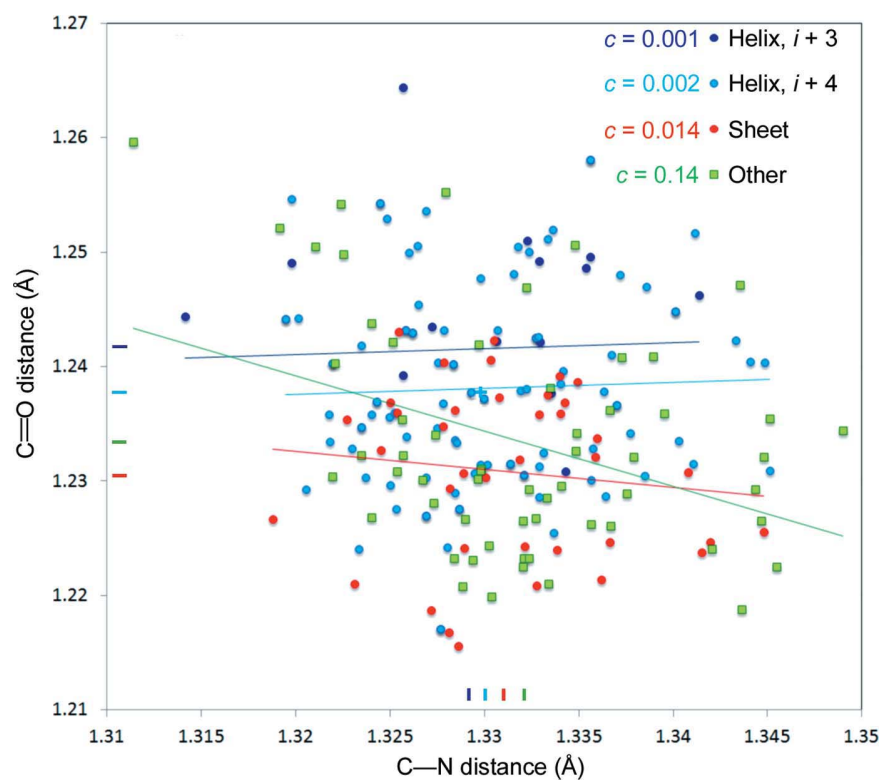

Figure 17

Scatter diagram of the $\mathrm{C}-\mathrm{N}$ versus $\mathrm{C}=\mathrm{O}$ bond lengths in the ChOx structure.

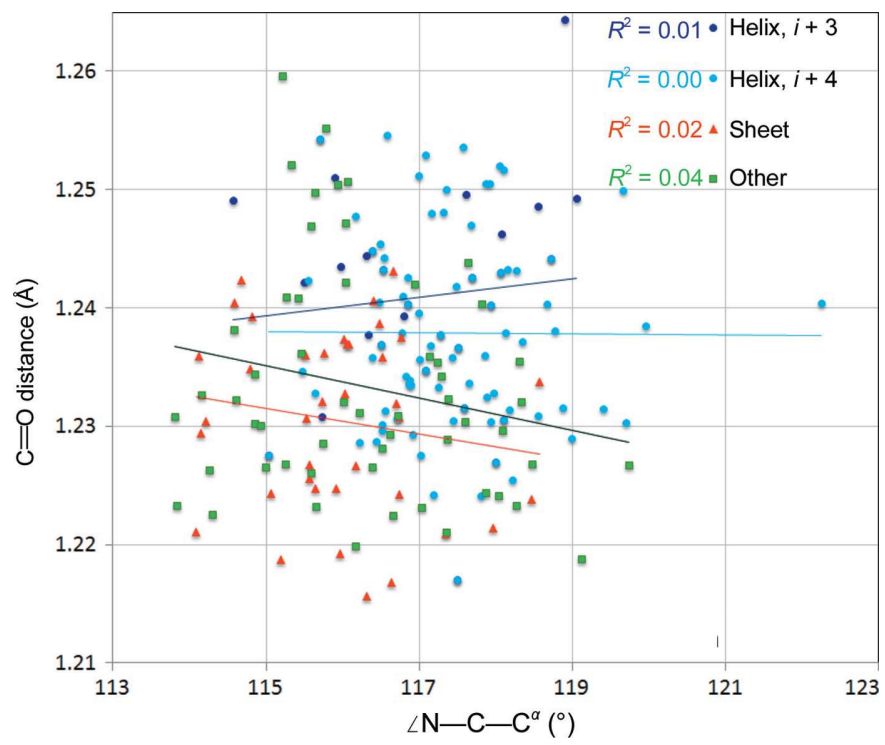

Figure 18

Scatterplot of the $\mathrm{C}=\mathrm{O}$ distances versus the $\angle \mathrm{C}^{\alpha}-\mathrm{C}-\mathrm{N}$ angles. The linear fits are shown to highlight the average values of distances (despite correlation coefficients of close to zero between the two variables).
Significant discrepancies were evident between the mean $\mathrm{C}=\mathrm{O}$ bond lengths of the different secondary-structural elements in ChOx. The mean $\mathrm{C}=\mathrm{O}$ bond length for $\beta$-sheets is noticeably shorter among the values listed for the secondarystructural elements, as observed by Lario et al. (2003) for $\mathrm{ChOx}$ at a lower resolution. In contrast, for $\alpha$-helices the mean $\mathrm{C}=\mathrm{O}$ bond length for the $i+3$ type of hydrogen bonds is slightly longer than that of the conventional $i+4$ type of hydrogen bonds.

Table 4 also lists the statistical values for the other covalent bonds of the main-chain peptide. The r.m.s.d. of the $\mathrm{C}-\mathrm{C}^{\alpha}$ distances in the different samples is about $0.01 \AA$. However, some discrepancies are noteworthy.

Unlike the $\mathrm{C}=\mathrm{O}$ bond lengths, the three other covalent bond lengths have average lengths which are higher in the $\alpha$-helix $i+4$ type of hydrogen bond compared with the $i+3$ type. Overall, the mean bond lengths obtained for cholesterol oxidase are comparable with the other statistical values reported in Table 4 . With the exception of $\mathrm{C}-\mathrm{C}^{\alpha}$, the average main-chain bond distances in cholesterol oxidase lie between the 'high-resolution protein' values reported by Jaskolski et al. (2007) and the PHENIX target restraints.

The shortest mean value for the $\mathrm{C}-\mathrm{C}^{\alpha}$ bond lengths are observed in the case of $\beta$-sheets; the other distances in cholesterol oxidase are very close to the PHENIX target restraints. The shortest $\mathrm{C}-\mathrm{N}$ bond lengths are found for $\alpha$-helix residues; this may be related to the long $\mathrm{C}=\mathrm{O}$ bonds found for this secondary-structure element. For $\mathrm{N}-\mathrm{C}^{\alpha}$ bond lengths, the shortest mean value is observed for 'other' and $\beta$-sheet residues.

Globally for the whole protein, no significant correlation $(+4 \%)$ is observed between the $\angle \mathrm{C}^{\alpha}-\mathrm{C}-\mathrm{N}$ and $\mathrm{C}=\mathrm{O}$ bond lengths (Fig. 18). Nevertheless, the diagram for the secondarystructural elements reveals different trends. The correlation between the two geometric values is still small in each separate sample; however, the $\left(\angle \mathrm{C}^{\alpha}-\mathrm{C}-\mathrm{N}, \mathrm{C}=\mathrm{O}\right)$ points occupy different regions of the scatter plot. Residues in $\alpha$-helices have generally large $\angle \mathrm{C}^{\alpha}-\mathrm{C}-\mathrm{N}$ and $\mathrm{C}=\mathrm{O}$ values, while 'others' and those in $\beta$-sheets have low values. The average $\angle \mathrm{C}^{\alpha}-\mathrm{C}-$ $\mathrm{N}$ value is lowest in $\beta$-sheets $\left(115.9 \pm 1.1^{\circ}\right)$ and highest in $\alpha$-helices $\left(117.3 \pm 1.1^{\circ}\right)$

For the $\alpha$-helix $i+3$ type of hydrogen bond, a weak positive correlation $(+1 \%)$ is observed, while for $\beta$-sheets and 'others' the correlation is found to be slightly negative ( -2 and $-4 \%$, respectively). For $\alpha$-helix $i+4$ residues, the $\mathrm{C}=\mathrm{O}$ bond lengths seem to be constant with the variation in the $\angle \mathrm{C}^{\alpha}-$ $\mathrm{C}-\mathrm{N}$ angle.

Electronic effects within the peptide bonds play meaningful roles in hydrogen bonding within protein structures. The polarization of the $\mathrm{C}=\mathrm{O}$ bonds is also influenced by other interactions within the protein and the solvent. An influential contribution of the imine resonance form to the geometry, which allows the $\mathrm{O}$ atoms to form stronger hydrogen bonds, could be expected. This is confirmed by the correlation found between the $\mathrm{C}=\mathrm{O}$ and $\mathrm{C}-\mathrm{N}$ bond lengths. It was found by Esposito et al. (2000) that in several protein structures at atomic resolution and in the CSD the correlation is strictly 
negative. This is found to be valid in the structure of cholesterol oxidase (Fig. 17), with a correlation of $14 \%$ and a negative slope of -0.48 between the $\mathrm{C}=\mathrm{O}$ and $\mathrm{C}-\mathrm{N}$ distances when only the 'other' regions are considered. However, correlation is found for $\alpha$-helix and $\beta$-sheet residues. Thus, the scatter plot only confirms for 'other' regions that the resonance of the peptide bond unit is shifted towards the imine form (short $\mathrm{N}-\mathrm{C}$ bond) as the $\mathrm{C}=\mathrm{O}$ distance increases. Similarly, $\mathrm{C}^{\alpha}-\mathrm{C}-\mathrm{N}$ angles and $\mathrm{C}=\mathrm{O}$ distances are found to be unrelated in $\alpha$-helices and $\beta$-sheets; only a very weak correlation (4\%) occurs for 'other' residues (Fig. 18).

\section{Conclusion}

It is very rare for a protein, especially of around 500 residues, to diffract to subatomic resolution, although with the improvement in data-collection, processing and refinement methods such structures are becoming more feasible. Despite these ultrahigh-resolution structures, it is still a significant challenge to study the electrostatic and stereochemical properties of proteins. However, these challenges can be overcome, in part, by using the transferability principle. The principle, in which a better refined model is obtained and the electrostatic properties can be studied on the basis of the transferred multipolar electron-density parameters, has already been discussed (Zarychta et al., 2007; Domagała et al., 2011, 2012; Dittrich et al., 2005; Volkov et al., 2004). The diffraction of macromolecular structures to atomic or lower resolution no longer poses an obstacle for the study of the electrostatic properties using a multipolar atom model.

Here, a relatively large protein is studied at subatomic resolution. The refinement statistics and the Ramachandran plot show that the refined model is acceptable. To study the electrostatic potential of the active site and to investigate the interactions between the protein and the ligand, experimental electron-density database transfer was taken into account. The results obtained on the basis of database transfer show that the active site has an overall positive electrostatic potential, which is complemented by an overall negative electrostatic potential of the cofactor. The numerous hydrogen bonds found between the ligand and the protein are in agreement with the specificity of this class of proteins for the FAD cofactor.

\section{Acknowledgements}

BZ is grateful for four months of invited professor position. MA thanks the Higher Education Commission of Pakistan for $\mathrm{PhD}$ funding. PM is grateful for grant PIIF-GA-2008-219380 'ProteinChargeDensity'.

\section{References}

Abramov, Y. A. (1997). Acta Cryst. A53, 264-272.

Afonine, P. V., Grosse-Kunstleve, R. W., Adams, P. D., Lunin, V. Y. \& Urzhumtsev, A. (2007). Acta Cryst. D63, 1194-1197.

Afonine, P. V., Grosse-Kunstleve, R. W., Echols, N., Headd, J. J., Moriarty, N. W., Mustyakimov, M., Terwilliger, T. C., Urzhumtsev, A., Zwart, P. H. \& Adams, P. D. (2012). Acta Cryst. D68, 352-367.
Afonine, P. V., Lunin, V. Y., Muzet, N. \& Urzhumtsev, A. (2004). Acta Cryst. D60, 260-274.

Ahmed, M., Jelsch, C., Guillot, B., Lecomte, C. \& Domagała, S. (2013). Cryst. Growth Des. 13, 315-325.

Allen, F. H. (2002). Acta Cryst. B58, 380-388.

Allen, F. H., Watson, D. G., Brammer, L., Orpen, A. G. \& Taylor, R. (2006). International Tables for Crystallography, Vol. C, 1st online ed., edited by E. Prince, pp. 790-811. Chester: International Union of Cystallography.

Arunan, E., Desiraju, G. R., Klein, R. A., Sadlej, J., Scheiner, S., Alkorta, I., Clary, D. C., Crabtree, R. H., Dannenberg, J. J., Hobza, P., Kjaergaard, H. G., Legon, A. C., Mennucci, B. \& Nesbitt, D. J. (2011). Pure Appl. Chem. 83, 1637-1641.

Av-Gay, Y. \& Sobouti, R. (2000). Can. J. Microbiol. 46, 826-831.

Bader, R. (1991). Chem. Rev. 91, 893-928.

Baker, E. N. \& Hubbard, R. E. (1984). Prog. Biophys. Mol. Biol. 44, 97-179.

Berman, H. M. (2000). Nucleic Acids Res. 28, 235-242.

Bernstein, F. C., Koetzle, T. F., Williams, G. J., Meyer, E. F. Jr, Brice, M. D., Rodgers, J. R., Kennard, O., Shimanouchi, T. \& Tasumi, M. (1977). J. Mol. Biol. 112, 535-542.

Bolen, D. W. \& Rose, G. D. (2008). Annu. Rev. Biochem. 77, 339-362. Bondi, A. (1964). J. Phys. Chem. 68, 441-451.

Case, D. A. et al. (2008). AMBER10. University of California, San Francisco, USA.

Cavener, D. R. (1992). J. Mol. Biol. 223, 811-814.

Chen, V. B., Arendall, W. B., Headd, J. J., Keedy, D. A., Immormino, R. M., Kapral, G. J., Murray, L. W., Richardson, J. S. \& Richardson, D. C. (2010). Acta Cryst. D66, 12-21.

Chen, L., Lyubimov, A. Y., Brammer, L., Vrielink, A. \& Sampson, N. S. (2008). Biochemistry, 47, 5368-5377.

Chothia, C. (1984). Annu. Rev. Biochem. 53, 537-572.

Corbin, D. R., Grebenok, R. J., Ohnmeiss, T. E., Greenplate, J. T. \& Purcell, J. P. (2001). Plant Physiol. 126, 1116-1128.

Corbin, D. R., Greenplate, J. T. \& Purcell, J. P. (1998). HortScience, 33, 614-617.

Coulombe, R., Yue, K. Q., Ghisla, S. \& Vrielink, A. (2001). J. Biol. Chem. 276, 30435-30441.

Desiraju, G. R. (1991). Acc. Chem. Res. 24, 290-296.

Dittrich, B., Hübschle, C. B., Messerschmidt, M., Kalinowski, R., Girnt, D. \& Luger, P. (2005). Acta Cryst. A61, 314-320.

Domagała, S., Fournier, B., Liebschner, D., Guillot, B. \& Jelsch, C. (2012). Acta Cryst. A68, 337-351.

Domagała, S., Munshi, P., Ahmed, M., Guillot, B. \& Jelsch, C. (2011). Acta Cryst. B67, 63-78.

Dominiak, P. M., Volkov, A., Dominiak, A. P., Jarzembska, K. N. \& Coppens, P. (2009). Acta Cryst. D65, 485-499.

Emsley, P., Lohkamp, B., Scott, W. G. \& Cowtan, K. (2010). Acta Cryst. D66, 486-501.

Engh, R. A. \& Huber, R. (1991). Acta Cryst. A47, 392-400.

Espinosa, E. \& Molins, E. J. (2000). J. Chem. Phys. 113, 5686-5694.

Esposito, L., Vitagliano, L., Zagari, A. \& Mazzarella, L. (2000). Protein Eng. Des. Sel. 13, 825-828.

Flegg, H. M. (1973). Ann. Clin. Biochem. 10, 79-84.

Guillot, B. (2011). Acta Cryst. A67, C511-C512.

Guillot, B., Jelsch, C., Podjarny, A. \& Lecomte, C. (2008). Acta Cryst. D64, 567-588.

Guillot, B., Muzet, N., Artacho, E., Lecomte, C. \& Jelsch, C. (2003). J. Phys. Chem. B, 107, 9109-9121.

Hansen, N. K. \& Coppens, P. (1978). Acta Cryst. A34, 909-921.

Held, J. \& van Smaalen, S. (2014). Acta Cryst. D70, 1136-1146.

Housset, D., Benabicha, F., Pichon-Pesme, V., Jelsch, C., Maierhofer, A., David, S., Fontecilla-Camps, J. C. \& Lecomte, C. (2000). Acta Cryst. D56, 151-160.

Jaskolski, M., Gilski, M., Dauter, Z. \& Wlodawer, A. (2007). Acta Cryst. D63, 611-620.

Jelsch, C., Guillot, B., Lagoutte, A. \& Lecomte, C. (2005). J. Appl. Cryst. 38, 38-54. 
Jelsch, C., Pichon-Pesme, V., Lecomte, C. \& Aubry, A. (1998). Acta Cryst. D54, 1306-1318.

Jelsch, C., Teeter, M. M., Lamzin, V., Pichon-Pesme, V., Blessing, R. H. \& Lecomte, C. (2000). Proc. Natl Acad. Sci. USA, 97, 31713176.

Johnas, S. K. J., Dittrich, B., Meents, A., Messerschmidt, M. \& Weckert, E. F. (2009). Acta Cryst. D65, 284-293.

Karplus, P. A. \& Diederichs, K. (2012). Science, 336, 1030-1033.

Kass, I. J. \& Sampson, N. S. (1998). Biochemistry, 37, 17990-18000.

Klebe, G. (1994). J. Mol. Biol. 237, 212-235.

Koch, O., Bocola, M. \& Klebe, G. (2005). Proteins, 61, 310-317.

Lario, P. I., Sampson, N. \& Vrielink, A. (2003). J. Mol. Biol. 326, 16351650.

Lario, P. I. \& Vrielink, A. (2003). J. Am. Chem. Soc. 125, 12787-12794.

Liebschner, D., Jelsch, C., Espinosa, E., Lecomte, C., Chabrière, E. \& Guillot, B. (2011). J. Phys. Chem. A, 115, 12895-12904.

Liu, Q., Huang, Q., Teng, M., Weeks, C. M., Jelsch, C., Zhang, R. \& Niu, L. (2003). J. Biol. Chem. 278, 41400-41408.

Lyubimov, A. Y., Chen, L., Sampson, N. S. \& Vrielink, A. (2009). Acta Cryst. D65, 1222-1231.

Lyubimov, A. Y., Heard, K., Tang, H., Sampson, N. S. \& Vrielink, A. (2007). Protein Sci. 16, 2647-2656.

Lyubimov, A. Y., Lario, P. I., Moustafa, I. \& Vrielink, A. (2006). Nature Chem. Biol. 2, 259-264.

MacArthur, M. W. \& Thornton, J. M. (1996). J. Mol. Biol. 264, 11801195.

Mallinson, P. R., Smith, G. T., Wilson, C. C., Grech, E. \& Wozniak, K. (2003). J. Am. Chem. Soc. 125, 4259-4270.

Meot-Ner, M. \& Sieck, L. W. (1986). J. Am. Chem. Soc. 108, 75257529.

Munshi, P. \& Guru Row, T. N. (2005). CrystEngComm, 7, 608-611.

Muzet, N., Guillot, B., Jelsch, C., Howard, E. \& Lecomte, C. (2003). Proc. Natl Acad. Sci. USA, 100, 8742-8747.

Navas, J., González-Zorn, B., Ladrón, N., Garrido, P. \& VázquezBoland, J. A. (2001). J. Bacteriol. 183, 4796-4805.
Pflugrath, J. W. (1999). Acta Cryst. D55, 1718-1725.

Ramachandran, G. N., Ramakrishnan, C. \& Sasisekharan, V. (1963). J. Mol. Biol. 7, 95-99.

Sampson, N. \& Vrielink, A. (2003). Acc. Chem. Res. 36, 713722.

Schmidt, A., Jelsch, C., Ostergaard, P., Rypniewski, W. \& Lamzin, V. S. (2003). J. Biol. Chem. 278, 43357-43362.

Shen, Z., Corbin, D. R., Greenplate, J. T., Grebenok, R. J., Galbraith, D. W. \& Purcell, J. P. (1997). Arch. Insect Biochem. Physiol. 34, 429-442.

Stadtman, T. C., Cherkes, A. \& Anfinsen, C. B. (1954). J. Biol. Chem. 206, 511-523.

Stickle, D. F., Presta, L. G., Dill, K. A. \& Rose, G. D. (1992). J. Mol. Biol. 226, 1143-1159.

Subramanian, S. \& Zaworotko, M. J. (1994). Coord. Chem. Rev. 137, 357-401.

Thomas, A., Benhabiles, N., Meurisse, R., Ngwabije, R. \& Brasseur, R. (2001). Proteins, 43, 37-44.

Urzhumtseva, L., Klaholz, B. \& Urzhumtsev, A. (2013). Acta Cryst. D69, 1921-1934.

Vaguine, A. A., Richelle, J. \& Wodak, S. J. (1999). Acta Cryst. D55, 191-205.

Volkov, A., Li, X., Koritsanszky, T. \& Coppens, P. (2004). J. Phys. Chem. A, 108, 4283-4300.

Vrielink, A. \& Ghisla, S. (2009). FEBS J. 276, 6826-6843.

Wilson, A. J. C. (1942). Nature (London), 150, 152.

Winn, M. D. et al. (2011). Acta Cryst. D67, 235-242.

Wood, P. A., Pidcock, E. \& Allen, F. H. (2008). Acta Cryst. B64, 491-496.

Yin, Y., Sampson, N. S., Vrielink, A. \& Lario, P. I. (2001). Biochemistry, 40, 13779-13787.

Yue, Q. K., Kass, I. J., Sampson, N. S. \& Vrielink, A. (1999). Biochemistry, 38, 4277-4286.

Zarychta, B., Pichon-Pesme, V., Guillot, B., Lecomte, C. \& Jelsch, C. (2007). Acta Cryst. A63, 108-125. 